\title{
Simulation modeling and statistical classification of escarpment planforms
}

\author{
Alan D. Howard \\ Department of Environmental Sciences, University of Virginia, Charlottesville, VA 22903, USA
}

Received 21 March 1994; revised 30 September 1994; accepted 10 October 1994

\begin{abstract}
Nearly horizontal sedimentary sequences are typically eroded into escarpments capped by resistant rock layers. These escarpments record in planform the spatial variation in erosional processes. Simulation models have been constructed of scarp development by three processes, scarp backwasting, fluvial erosion, and groundwater sapping, acting singly or in combination. Scarp backwasting produces planforms characterized by broad, shallow reentrants and sharply pointed headlands. Fluvial erosion creates dendritic, sharply terminated canyons which gradually widen downstream because of superimposed backwasting. Groundwater sapping produces weakly branched canyons of nearly constant width with generally rounded headwalls. A number of morphometric variables are measured on natural and simulated scarps as well as lava flows, glacially eroded mountain fronts, and eroded tabular igneous intrusions. A discriminant analysis is able to classify 478 of these planforms into 9 categories with $87 \%$ accuracy.
\end{abstract}

\section{Introduction}

Many landforms exhibit distinct boundaries between dissimilar terrain and can be well characterized by planimetric outlines. Examples include the outlines of escarpments and deep valleys, the shorelines of islands or lakes, the edges of basalt flows, drumlins, fluvial islands, some dune types, meteoric impact basins, tectonic basins and collapse depressions (sinkholes, periglacial alases, etc.). In some cases, such as remotely sensed images of planets and satellites, little information other than planform morphology is available to infer formative processes.

The planimetric outline records the spatial variation in the processes creating the landform. The present paper addresses the information content of such outlines: Can the processes responsible for a planimetric shape be inferred from statistical characteristics of the outline? Most attention will be devoted to a particular class of landform boundary - escarpments created by lateral retreat of scarps in layered rocks, that is, Schumm and Chorley's compound scarps (Schumm and Chorley, 1966) consisting of one resistant layer sandwiched between easily eroded rocks that are either nearly horizontal or uniformly dipping.

Three major processes of scarp backwasting are identified: uniform backwasting, fluvial incision, and groundwater sapping. A simulation model of scarp retreat is introduced that incorporates the spatial pattern of these processes, acting alone or in combination. The simulated scarps are statistically compared with natural scarps using a multivariate suite of variables measuring planform shape. In addition to compound scarps, outlines of a few other landform types are included to test the discriminating power of the variables, including contours from areas of uniform relief, meandering 
stream planforms, edges of lava flows, and mountain fronts strongly modified by glacial erosion.

This approach to characterize scarp morphology is similar to that used earlier by Howard and Hemberger (1991) for stream meanders - define a wide range of measurement techniques and associated variables and through statistical analysis determine which are useful in summarizing the morphological variation between classes of scarps formed by different processes. The variables most useful for distinguishing between scarp classes characterize the spatial series of direction changes (curvature) as well as the size distribution and shape of headlands and reentrants. The planimetric outline will be shown to carry significant information content about the processes creating it, such that the morphometric variables can distinguish between scarps formed by different process rate laws with reasonable accuracy.

\section{Modeling of scarp planform evolution}

The planforms of natural canyons and escarpments in layered rocks are quite varied, exhibiting characteristic shapes such as reentrants, projections, and inset canyons. Some scarps have rounded projections, or headlands, whereas others are sharply pointed; some are deeply incised by deep, narrow canyons while others have shallow, broadly rounded reentrants. The scarp form is determined by the spatial distribution of erosion and by lithologic and structural influences such as rock thickness and dip (Howard and Selby, 1994).

The rate of scarp retreat may vary from place to place because of variations in rock resistance. Such variability tends to occur either at relatively small scales (e.g.. variations in density of caprock fracturing; Nicholas and Dixon, 1986) or at a very large scale because of lateral variations in caprock thickness or lithology.

At the intermediate scales discussed in this research. the main factor controlling scarp form is areal variations in process rates. Erosion of the scarp face by rockfall, slumping, and undermining of the caprock, weathering of the caprock debris and erosion of subcaprock units will be termed scarp backwasting. These backwasting processes are assumed not to depend upon the landform morphology or processes acting behind the brink of the scarp on the top or backslopes of the escarpment. Deep reentrant canyons are created by rapid erosion along a linear zone, generally by fluvial erosion or groundwater sapping. Both of these processes depend upon water flow collected from the top or backslopes of the scarp. Structure often plays an indirect role by channeling surface or subsurface water along fractures. The role of areal variations in intensity of these three classes of processes in creating scarp planforms is illustrated by simulation modeling followed by multivariate comparison of the resulting scarp planforms with natural scarps.

\subsection{Scarp backwasting}

Natural scarps commonly exhibit sharply pointed, or cuspate projections (headlands, spurs) and broadly concave reentrants (embayments). The role of essentially uniform rates of scarp retreat in creating pointed headlands and broad embayments was first discussed by Dutton (1882, pp. 258-259) and Davis (1901, pp. 178-180), who noted the nearly uniform spacing between successively lower scarps on the walls of the Grand Canyon. Attack of an escarpment by areally uniform backwasting gradually makes embayments more shallow and the planform of the scarp face close to linear. Similar observations were made by Howard (1970) and Schipull (1980). Lange (1959) systematically studied the consequences of uniform erosional attack, which he called "uniform decrescence", on two- and three-dimensional surfaces, and demonstrated that uniform erosion acting on any arbitrary, rough surface produces rounded reentrants and cuspate spurs. He also showed that scarp retreat in the Grand Canyon is uniform to a first approximation, with some tendency towards more rapid erosion of embayments. Further-

Fig. 1. Scarp formed by backwasting, with hypothetical erosion and reconstruction of the mesa. (A) Hypothetical erosion of the mesa (outer heavy line) by uniform backwasting eventually produces the stippled remnant with shallow, curving reentrants and sharp headlands. (B) An attempt to reproduce the original scarp by uniform addition of material is unsuccessful because these processes are not reversible. Only the possible minimum dimensions of the original escarpment can be inferred from an eroded remnant. South Caineville Mesa, Utah (Hanksville, UT and Loa, UT 1:100,000 quandrangles: natural scarps are generally identified by the 1:100,000 or 1:250,000 scale map on which they occur, although mapping utilized larger scale maps ). 
(A)

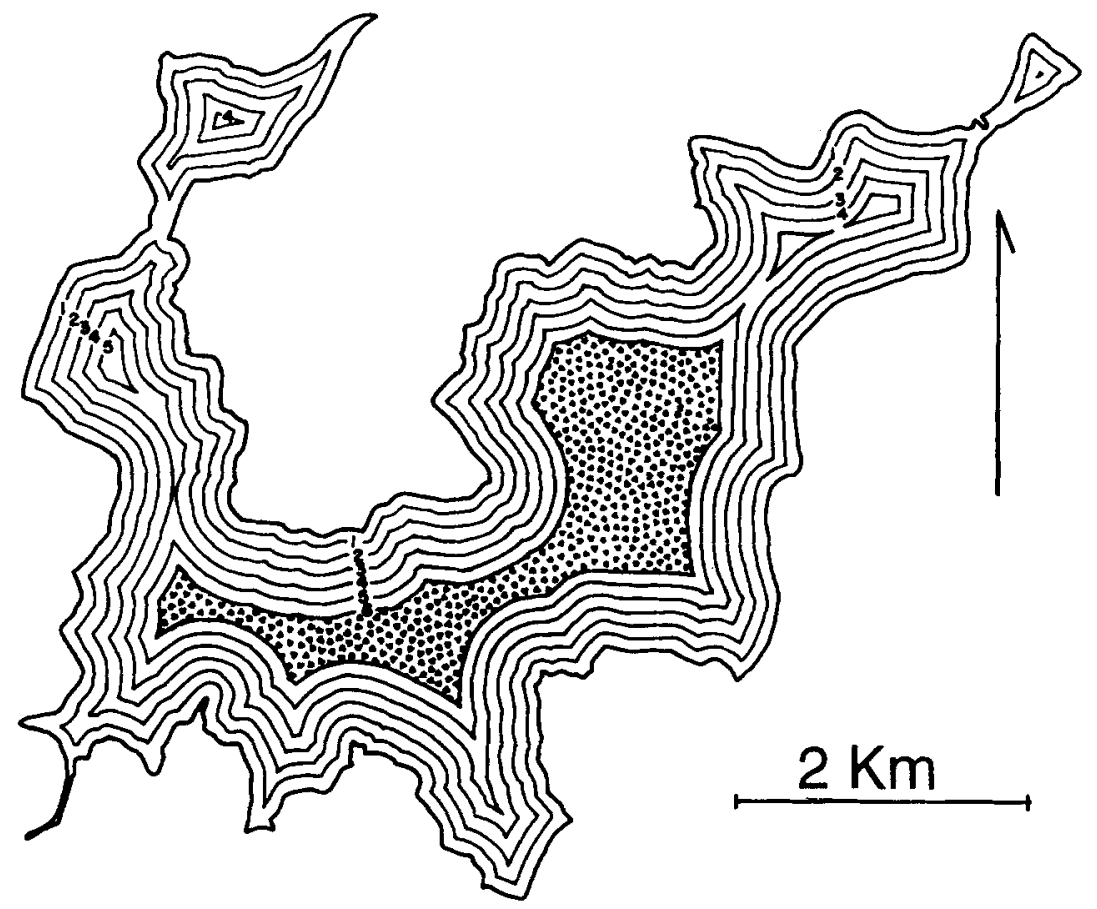

(B)

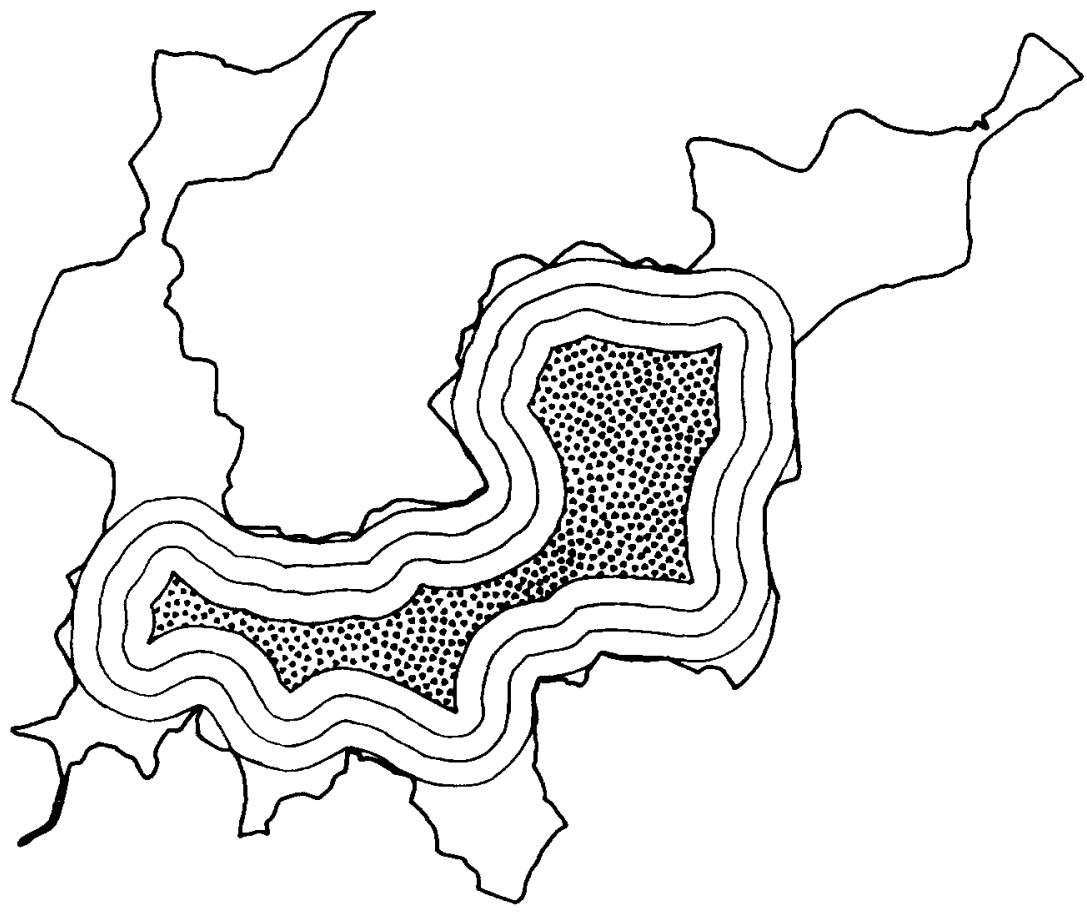


more, uniform decrescence and uniform addition of material (accrescence) are not reversible (Lange. 1959). The position of an escarpment rim during the past cannot be uniquely inferred from its present configuration (Fig. 1), even if subject to uniform retreat in the past, especially in the case of former spurs that are first eroded into outliers and then wasted away.

A simple numerical model of scarp backwasting lumps local variations in process rates and rock resistance into a single "erodibility", which is assumed to vary randomly from location to location. The erodibility is assumed to be self-similar, or fractal, with variations at both large and small scales, and is generated using a 2-D recursive midpoint subdivision procedure similar to that used by Goodchild (1980). Fournier et al. (1982), Kirkby (1986) and Lam and De Cola (1993b). The spatial variability of erodibility is characterized by three parameters, an average value, a variance, and a rate of change of variance with scale (related to the fractal dimension). The rate of lateral backwasting, $\partial n / \partial t$, is assumed to equal the erodibility. $C_{c}$ :

in $/ \partial t=C$

where $n$ is the direction normal to the scarp in the horizontal $(x, y)$ plane. The rate of scarp backwasting is assumed to vary spatially with variations in $C_{\mathrm{e}}$, but $C_{c}$ is assumed not to vary temporally.

The simulation model uses a square matrix of points with dimensions of $50 \times 50$ or $100 \times 100$. Initially the scarp is specified to be located at the matrix boundaries, giving a square "mesa". At any time matrix points are classified by whether they lie beyond the scarp edge (exterior points) or within the scarp interior. To provide a spatial resolution exceeding the matrix cell size. the scarp front relative to exterior points located adjacent to interior points is recorded by vectors extending in the eight directions from the exterior points toward surrounding matrix locations. Scarp retreat, however. can only occur towards adjacent interior matrix locations. During each time step, the vectors are incremented according to the erosion rate law. If the new vector length exceeds the distance to the adjacent matrix location, that location is then changed to be an exterior point. The edge of the scarp is defined to be a convex surface joining the vectors at adjacent locations. Although natural scarps generally backwaste via discrete events such as rockfalls, the models presented below represent scarp retreat as a continuous process, assuming that the amount of backwasting per event on natural scarps is small compared to the overall dimensions of the scarp. The average amount of erosion per iteration is always assumed to be a small fraction of the matrix cell dimension.

Fig. 2 shows a plan view of successive scarp positions produced by uniform scarp retreat with fractally varying resistance: scarp retreat starts from the square matrix edges. As expected, scarps produced by this type of backwasting are characterized by sharply terminating projections and broad reentrants, with reentrants produced by erosion through more erodible rocks; similar features occur in the late stages of erosion of natural mesas (Fig. 1). In these simulations appreciable reentrants are created only when the erodibility has very strong areal variability on large spatial scales. Because of the fractal assumption, the attendant small-scale variance in erodibility creates simulated scarps that appear more irregular in detail than the natural scarps. Furthermore, in the Colorado Plateau region, natural scarps exhibiting a backwasting morphology of broad reentrants and sharp projections are generally developed in caprocks that are very uniform in thickness and degree of fracturing. This suggests that appreciable reentrants in natural scarps must result, in part, from concentrated erosional attack. The deep reentrants of natural scarps are largely inherited from fluvial or sapping erosion that were active during early stages of scarp retreat when large expanses of scarp top- or back-slopes contribute runoff or seepage, thereby locally accelerating backwasting rates. Simulations introduced below which combine backwasting with superimposed fluvial or groundwater sapping erosion exhibit this type of evolution.

The projections of some natural scarps are rounded rather than sharply pointed, which implies that the lateral erosion rates on the projections are enhanced relative to straight or concave portions of the scarp. Several mechanisms may account for this. The rate of erosion of many scarps is limited by the rate that debris shed from the cliff face can be weathered and removed from the underlying rampart on the less resistant rocks. Debris from convex portions of scarps (projections) is spread over a larger area of rampart and the rocks underlying the scarp rampart are more exposed to erosion. Additionally, headlands commonly stand in higher relief than reentrants, leading to enhanced ero- 


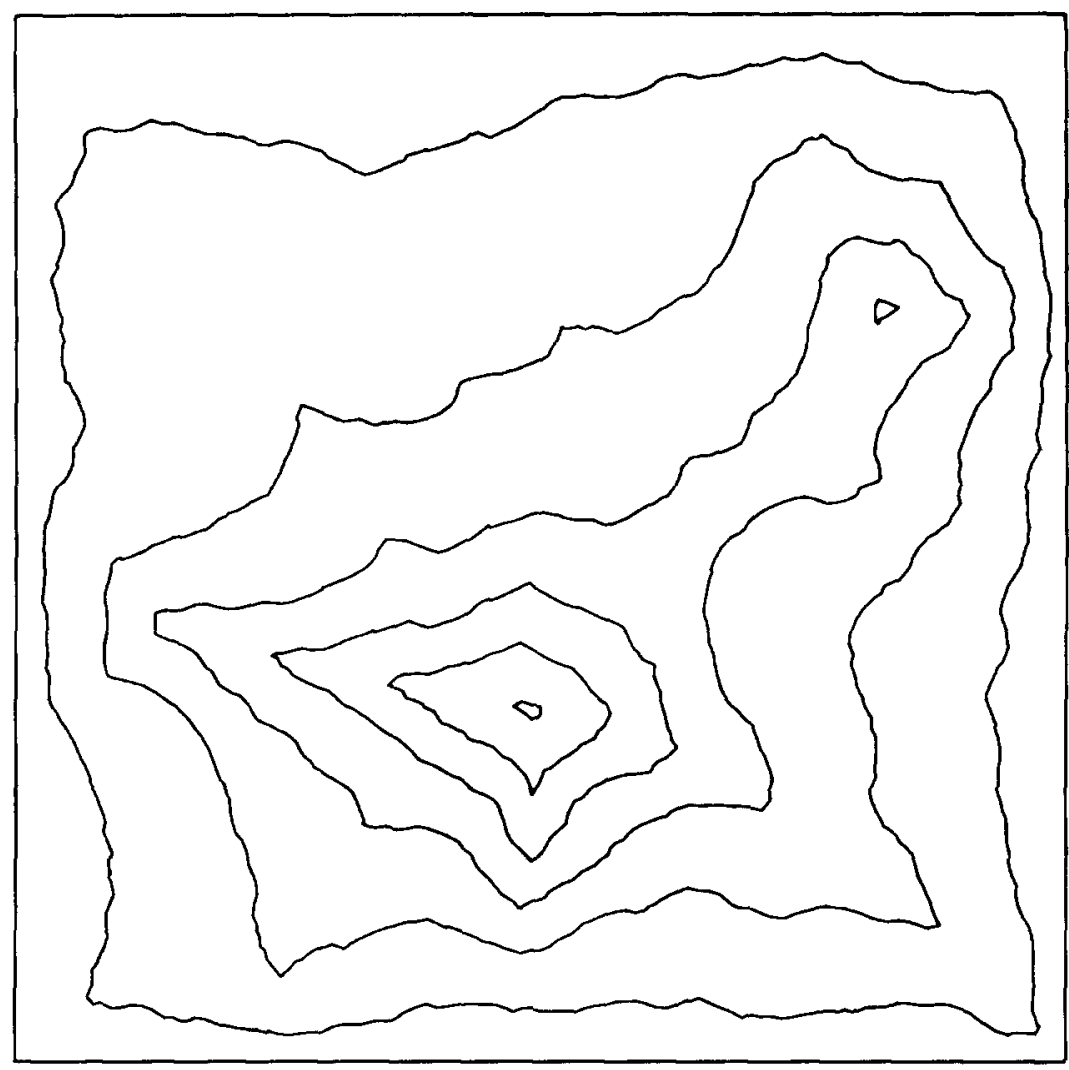

Fig. 2. Simulated scarp formed by backwasting with spatially variable resistance. Initial scarp position is the square edge of the matrix, and lines show successive positions of the scarp front.

sion of the steeper ramparts. Finally, some scarp caprock may be eroded by undermining because of the outward creep or weathering of the rocks beneath the caprock. Both processes are enhanced at convex scarp projections. Fig. 3 shows a model scarp in which backwasting rates are enhanced by scarp convexity and restricted by concavity. The northern extremities of the natural scarp in Fig. 4 show similarly rounded protuberances.

By contrast, some natural scarps exhibit narrow, talon-like headlands that are unlikely to have resulted from pure uniform retreat (Fig. 5). Occasional thin headlands may result from narrowing of divides between canyons by uniform backwasting, but where such sharp cusps are frequent, it is likely that they result from slowed erosion of narrow projections. Impedence of erosion on such headlands may result from a lack of uplands contributing surface or subsurface drainage to the scarp face, thus inhibiting chemical and physical weathering of the cliff face or its undermining. Scarps that have become broken up into numerous small buttes, such as occurs at Monument Valley, Arizona may be further examples of inhibition of scarp retreat where upland areas are small. An alternative explanation may be that these occur in locations with minimal caprock jointing, in the manner suggested by Nicholas and Dixon (1986).

Almost all escarpments in gently dipping rocks exhibit deep reentrants and, as erosion progresses, break up into isolated mesas and buttes. This indicates erosion concentrated along generally linear zones of structural weakness, fluvial erosion, or sapping (often acting in combination). Evidence for fluvial erosion or groundwater sapping is the asymmetry of scarps in gently tilted rocks. The planform of segments where the scarp faces up-dip is generally similar to that expected by uniform decrescence, because little drainage passes over the scarp, but segments facing downdip 


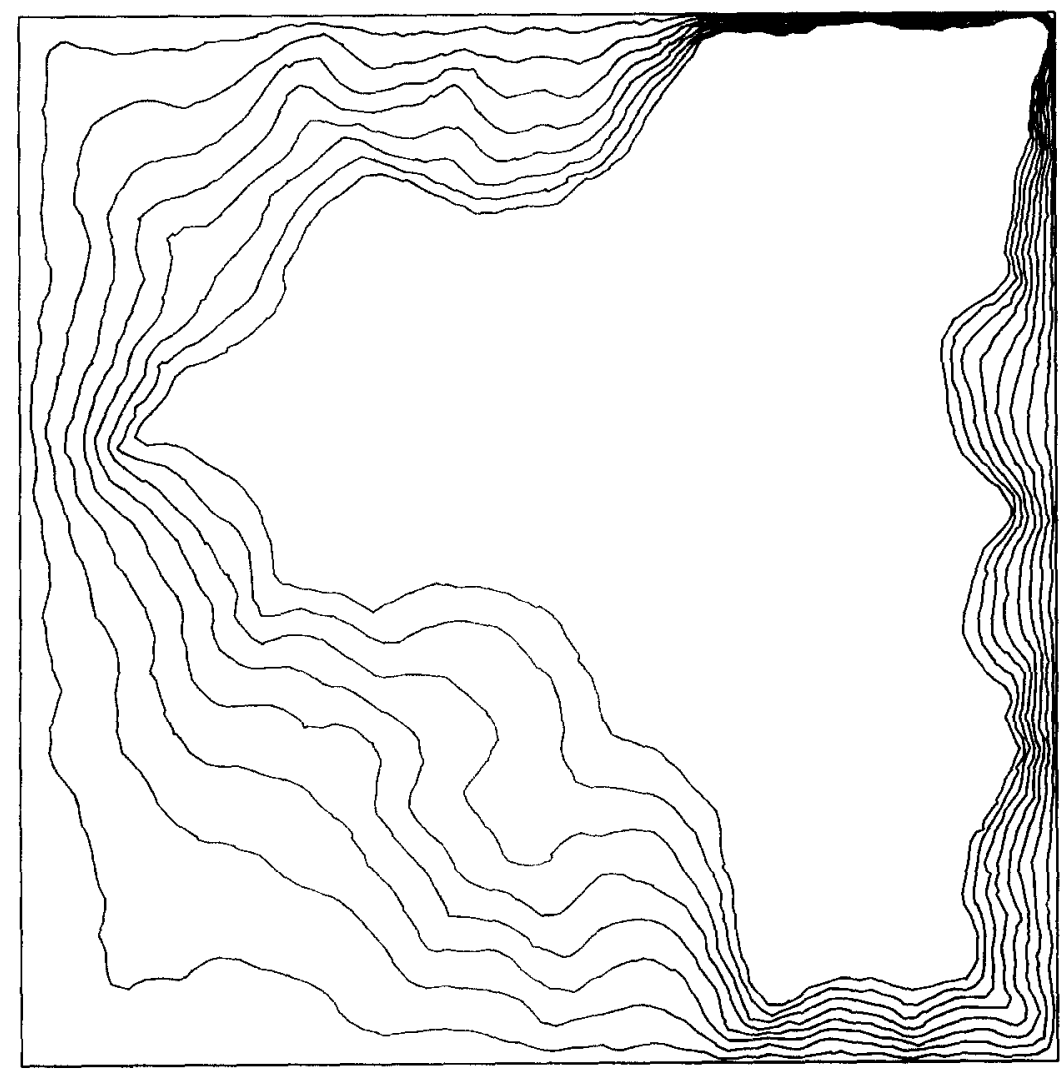

Fig. 3. Simulated scarp retreat with convexity-enhanced rate of backwasting.

("back scarps" of Ahnert, 1960) are deeply indented as the result of fluvial or sapping erosion (Fig. 5) (Ahnert, 1960; Laity and Malin, 1985).

\subsection{Fluvial incision}

One process creating deep reentrants is downcutting by streams which originate on the top of the escarpment and pass over the front of the escarpment. Such caprock erosion is limited to the width of the stream, which is generally small compared to overall scarp dimensions. The heads of fluvially eroded canyons are narrow, but downstream increase gradually in canyon width by scarp backwasting, as noted by Ahnert (1960), Laity and Malin (1985) and Schmidt (1980, 1988). Examples of such gradually narrowing, deep reentrants are common on the Colorado Plateau (Fig. 6).

Scarp erosion by combined fluvial erosion and scarp backwasting can be numerically modeled by superimposing a stream system onto a simulated scarp and allowing it to downcut through time. Streams flowing over the scarp are assumed to be bedrock floored and downcutting is detachment-limited. The downcutting rate is assumed to depend upon the drainage area, $A$, and local channel gradient, $S$ (Howard and Selby, 1994):

$$
\partial z / \partial t=C_{\mathrm{f}} A^{\gamma} S^{\eta}
$$

where $C_{\mathrm{f}}$ is bed erodibility, and $\gamma$ and $\eta$ are areally and temporally constant exponents. For these simulations $\gamma=0.35$ and $\eta=0.7$, in accordance with areally uniform production of runoff, and an erosion rate proportional to shear stress (Howard and Kerby, 1983). A stream network covering the entire matrix is generated by a random headward growth model starting from the matrix edges (Howard, 1971a) followed by stream capture (Howard, 1971b, 1990a). The network is then trimmed by deleting all channels whose contributing area is less than a critical value, $A_{\mathrm{c}}$. Thereafter the network is assumed to not change in extent or location. The evolution of the stream network profile is explicitly modeled using Eq. (2). It is assumed that the caprock 


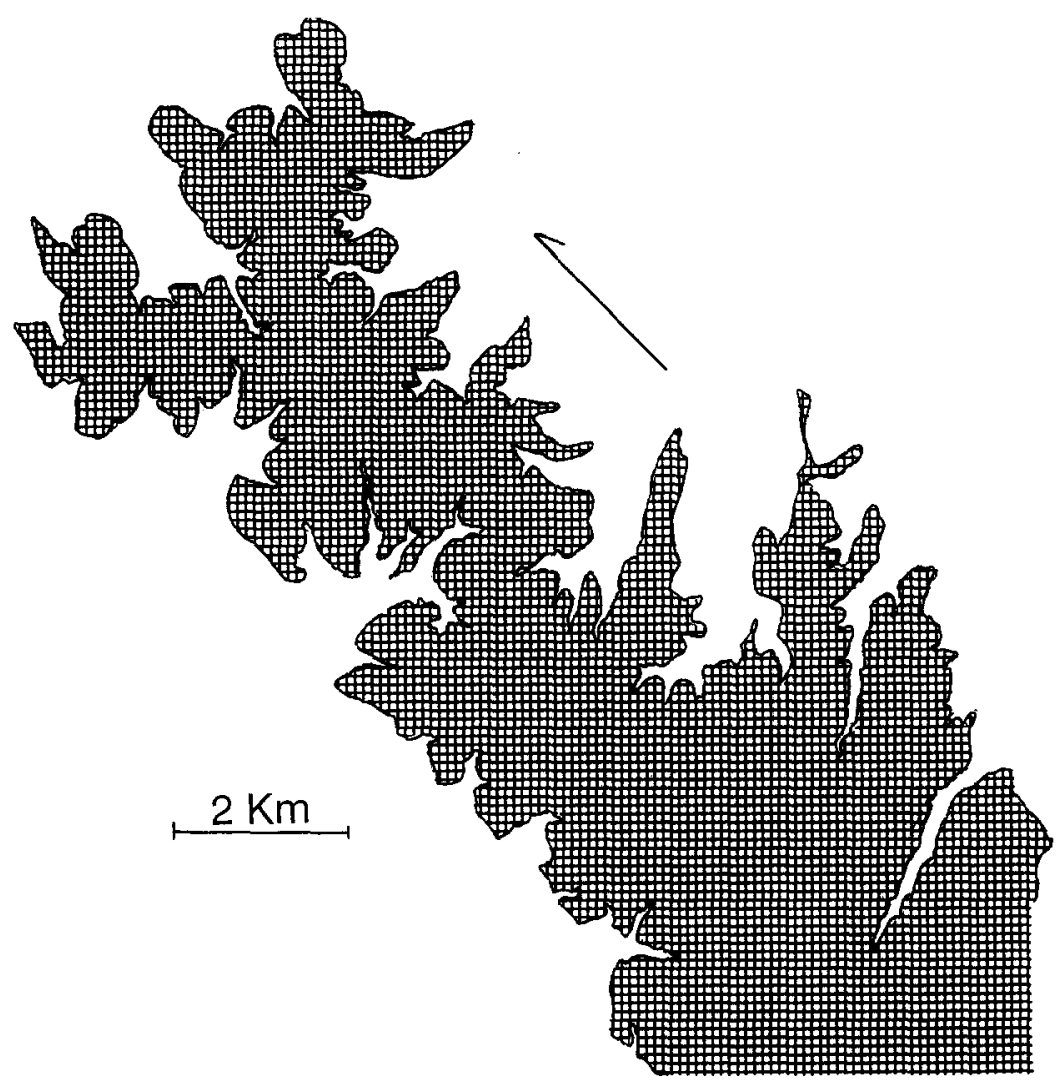

Fig. 4. Natural scarp with fluvially eroded reentrants and rounded projections. The interior, uneroded upland is patterned (Capulin Mountain, NM, 1:100,000 quadrangle ).

is overlain and underlain by rock of uniform erodibility $C_{\mathrm{fn}}$, whereas the caprock erodibility, $C_{\mathrm{fc}}$, is less. Initially the streams are assumed to have developed in the overlying rock with a steady state profile adjusted to a temporally constant rate of lowering of the matrix edges, $\partial z /\left.\partial t\right|_{\mathrm{e}}$. At the start of the simulation the elevation of the matrix edges is assumed to be just at the top of the caprock. As the matrix edges are lowered through and below the caprock, the overlying rock is rapidly stripped from the caprock and the streams develop a profile with a gently sloping section just above and in the top portion of the caprock, and an oversteepened section through and immediately below the caprock, as illustrated in the profile simulations of Howard (1972, 1988a). The edge of the caprock gradually retreats, most rapidly along larger streams. The edge of the scarp is defined as the intersection of the stream profile with the base of the caprock. In addition, it is assumed that the backwasting process, given by Eq. (1), is super- imposed on the fluvial downcutting so that the rate of scarp backwasting is given by:

$\frac{\partial n}{\partial t}=\frac{1}{S} \frac{\partial z}{\partial t}+C_{\mathrm{e}}$

where $\partial z / \partial t$ is given by Eq. (2), $C_{\mathrm{e}}$ is the general backwasting rate from Eq. (1), and the division by gradient, $S$, corrects vertical erosion to equivalent horizontal backwasting. The variable input parameters to the simulation are the critical drainage area $A_{c}$, the caprock resistance ratio, $C_{\mathrm{fc}} / C_{\mathrm{fn}}$, the backwastingdowncutting ratio, $C_{\mathrm{e}}: \partial z /\left.\partial t\right|_{\mathrm{e}}$, and the caprock thickness, $T$.

Fig. 7a shows a stream network and Fig. $7 b$ the simulated scarp eroded by fluvial downcutting along this stream network with superimposed scarp backwasting. Branched, gradually narrowing, and sharply terminated canyons result. The canyons are best defined during the middle stages of the simulation, but they 


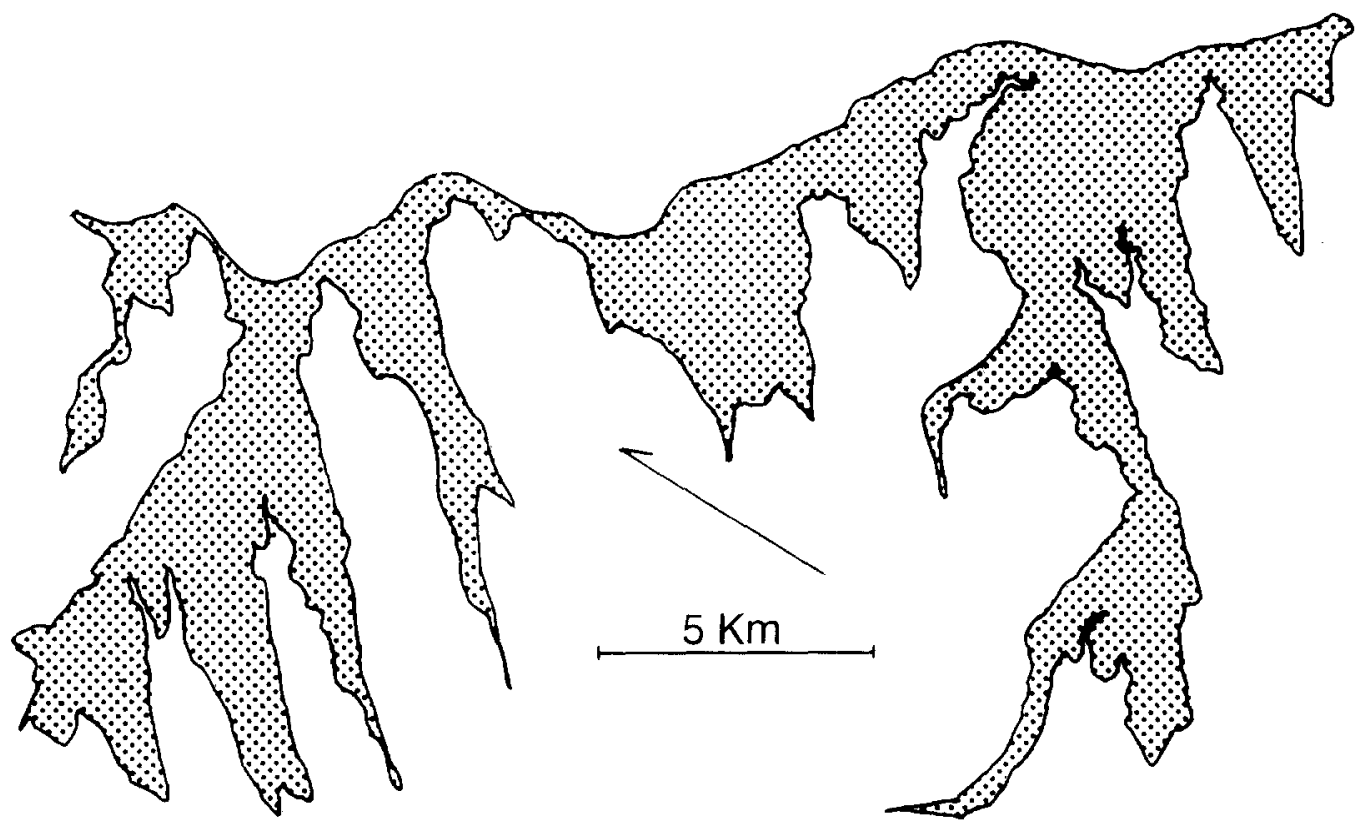

Fig. 5. Natural scarp with long, sharply pointed headlands. Rock dips slightly towards the southwest. The interior, uneroded upland is patterned (Hite Crossing, UT 1:100.000 quadrangle).

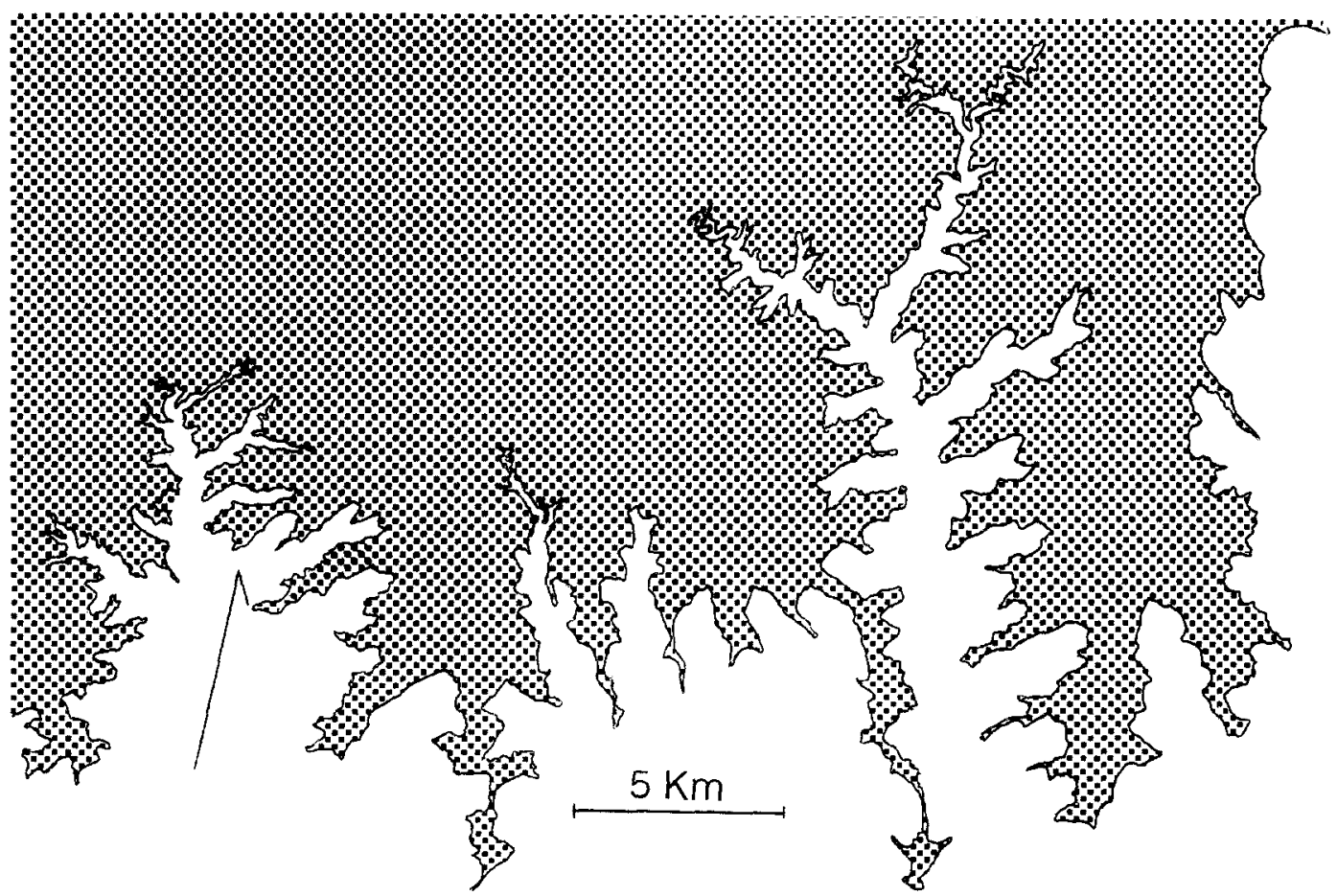

Fig. 6. Natural scarp with fluvially eroded reentrant canyons. The interior, uneroded upland is patterned (Smoky Mountain, UT 1:100,000 quadrangle). 

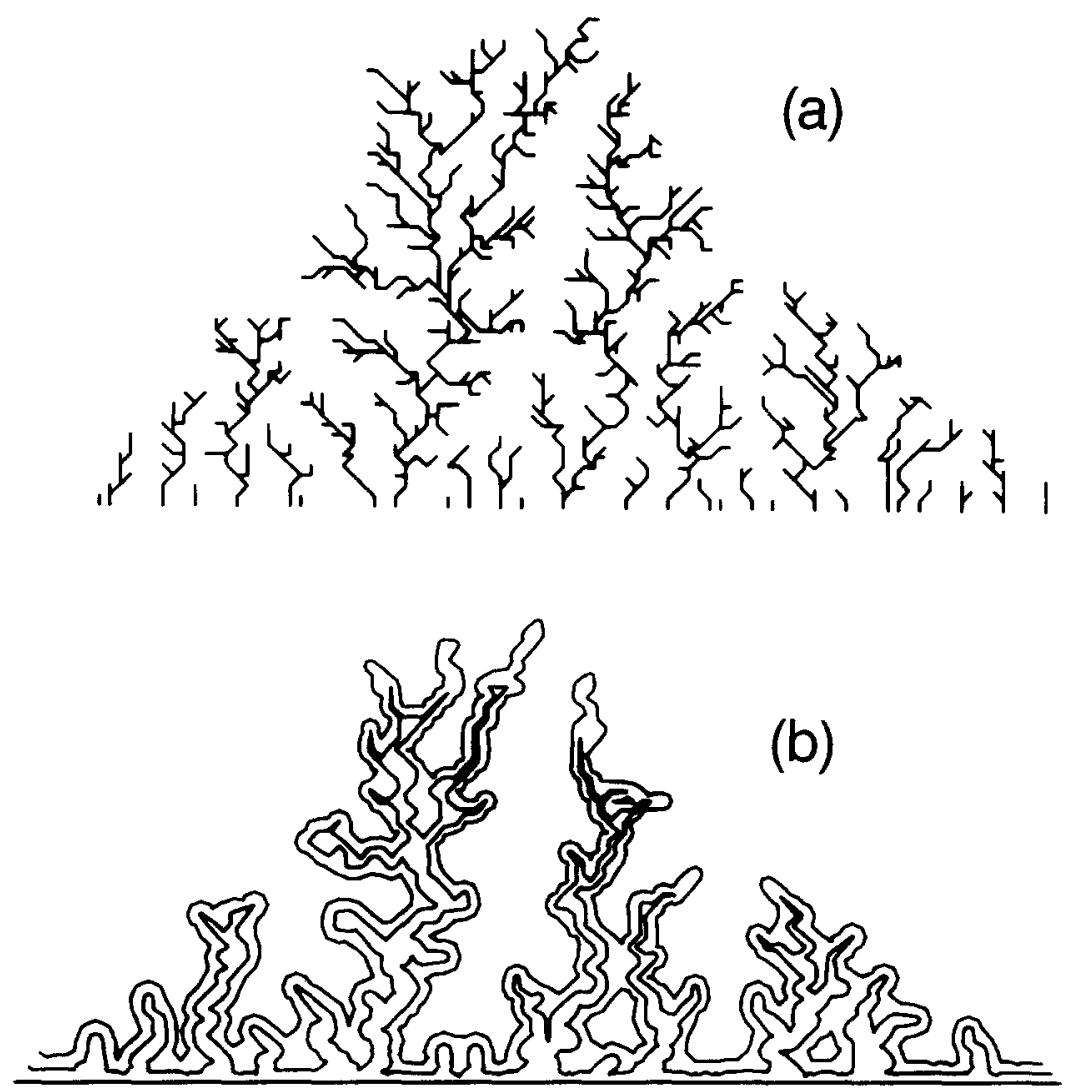

Fig. 7. Simulation of scarp erosion by fluvial erosion with superimposed backwasting. (a) The fluvial network. A minimum contributing area of 4 is used to define the sources. (b) The simulated planforms, starting from the square matrix edges. The illustration shows only the scarps eroded from one edge of an originally square mesa (as in Fig. 2).

gradually widen and lose definition during the final stages of scarp retreat as backwasting processes become dominant. Fig. 8 is similar but with convexityenhanced scarp backwasting. Figs. 6 and 4 are natural scarps similar to Figs. 7 and 8 , respectively.

\subsection{Groundwater sapping}

Groundwater sapping is an important process in scarp retreat throughout the Colorado Plateau, as suggested by Ahnert (1960) The deep, narrow, bluntly terminated canyon networks, of the type discussed by Laity and Malin (1985), Howard and Kochel (1988), and Baker et al. (1990), are the scarp forms most clearly dominated by sapping processes.

Ahnert (1960), Laity and Malin (1985), and Howard and Selby (1994) suggested that whereas fluvial erosion produced $\mathrm{V}$-shaped canyon heads that widen consistently downstream, sapping produced U-shaped, theater-headed canyons of relatively constant width downstream (the terms $\mathrm{U}$ - and V-shaped refer here to valley planform, not valley cross-section). Other planform features diagnostic of sapping-dominated canyon extension and widening include theater-shaped heads of first-order tributaries with active seeps, relatively constant valley width from source to outlet, high and steep valley sidewalls, pervasive structural control, and frequent hanging valleys. The most direct evidence of sapping processes are numerous alcoves, both in valley heads and along sidewalls, and springs on the valley walls and bottoms. Although many valley headwalls occur as deeply undercut alcoves, some terminate in $\mathrm{V}$ or half- $U$ shapes with obvious extension along major fractures.

A simulation model of scarp backwasting by groundwater sapping assumes a planar caprock aquifer (that may be tilted) with uniform areal recharge and a fractal areal variation in permeability. Recharge is assumed to 


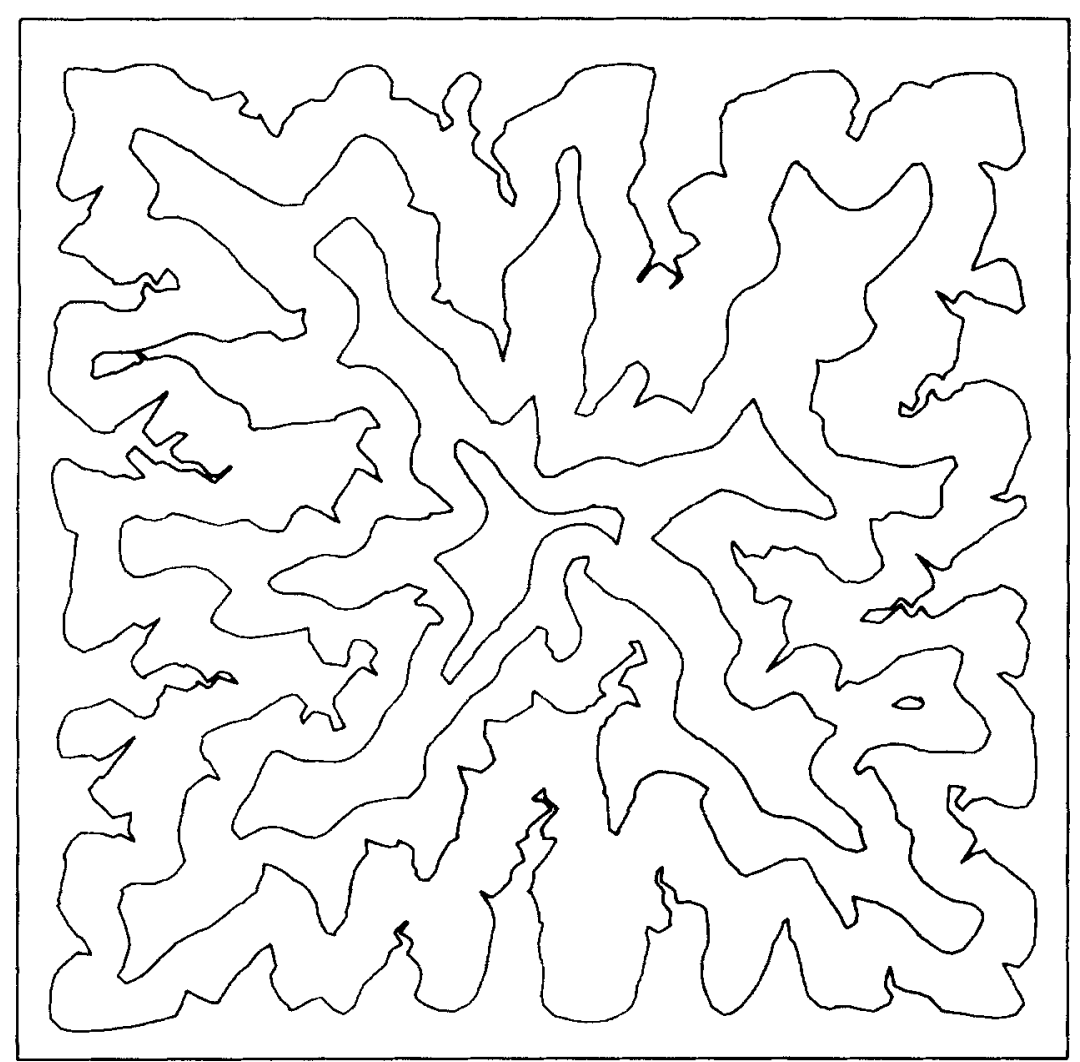

Fig. 8. Simulated scarp erosion by fluvial erosion with superimposed convexity-enhanced backwasting.

infiltrate vertically until it reaches a shallow aquifer perched on the base of the caprock, whereupon the flow is assumed to flow laterally to discharge along the scarp edges. Groundwater flow is assumed to follow the DuPuit approximation for shallow aquifers:

$\frac{\partial}{\partial x}\left(K\left(h-b_{x y}\right) \frac{\partial h}{\partial x}\right)+\frac{\partial}{\partial y}\left(K\left(h-b_{x y}\right) \frac{\partial h}{\partial y}\right)+R_{x y}=0$

where $x$ and $y$ are the matrix axes, $K$ is the isotropic but areally varying permeability, $h$ is the surface of the water table, $b_{x v}$ is the elevation of the aquifer base, and $R_{x y}$ is the recharge rate, which is usually assumed to be areally and temporally constant. For most simulations the caprock is assumed to be horizontal, and $b_{x v}$ is set to zero. For a few simulations $b_{x y}$ is assumed to slope linearly in the $y$-direction. The thickness of the water table $\left(h-b_{x y}\right)$ is assumed to be zero at the scarp edges. Finite difference techniques are used to solve for the groundwater flow field, with corrections for the case where scarp edges do not coincide exactly with matrixcell locations.
The rate of backwasting by sapping, $\partial n / \partial t$, is assumed to depend upon the amount by which the specific discharge at the scarp face $q$ exceeds a critical discharge $q_{\mathrm{c}}$ :

$\partial n / \partial t=C_{\mathrm{s}}\left(q-q_{\mathrm{c}}\right)^{a}+C_{\mathrm{e}}$

where $a$ is an exponent, $C_{\mathrm{s}}$ is a rate constant (assumed to be areally and temporally uniform), and $C_{\mathrm{e}}$ is the general backwasting rate from Eq. (1). Scarp erosion is simulated by solving for the ground water flow, eroding the scarp by a small amount, with repeated iterations. In the sapping simulations the permeability, $K$, is assumed to vary areally following a fractal distribution, but the intrinsic scarp erodibility is assumed to be areally uniform.

Fig. 9 shows the effect on simulated scarp form of varying the exponent $a$; in each of these simulations $q_{\mathrm{c}}=0$ and $C_{\mathrm{e}}=0$. As $a$ increases, the scarp form becomes more elaborated into deeper and more branched reentrants. Fig. 10 shows a natural scarp in 


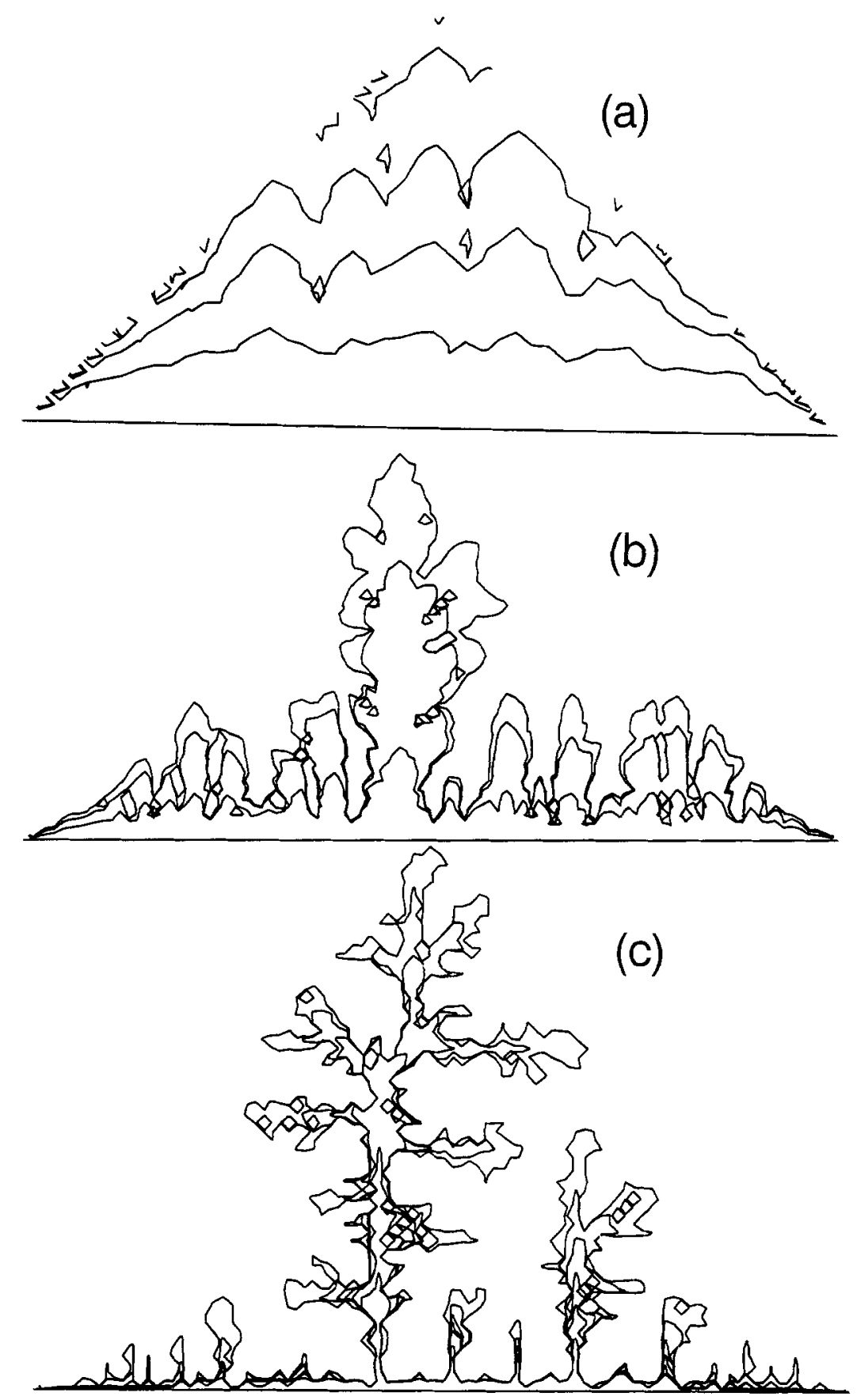

Fig. 9. Simulations of scarp retreat by groundwater sapping. The illustration shows only the scarps eroded from one edge of an originally square mesa. (a) Exponent $\alpha$ in Eq. (5) equals 0.5 ; (b) $\alpha=1.0$; (c) $\alpha=2.0$.

Navajo Sandstone formed largely by sapping, which suggests an effective value of $a$ greater than unity ( similar scarps are illustrated in the work by Laity and Malin, 1985; Howard and Kochel, 1988 and Howard and Selby, 1994). Groundwater sapping in cohesionless sand (Howard, 1988b) produces simple parallel reentrants similar to Fig. $9 \mathrm{~b}$, and suggests that $\alpha \approx 1$ for this case. Valleys developed by groundwater sapping 


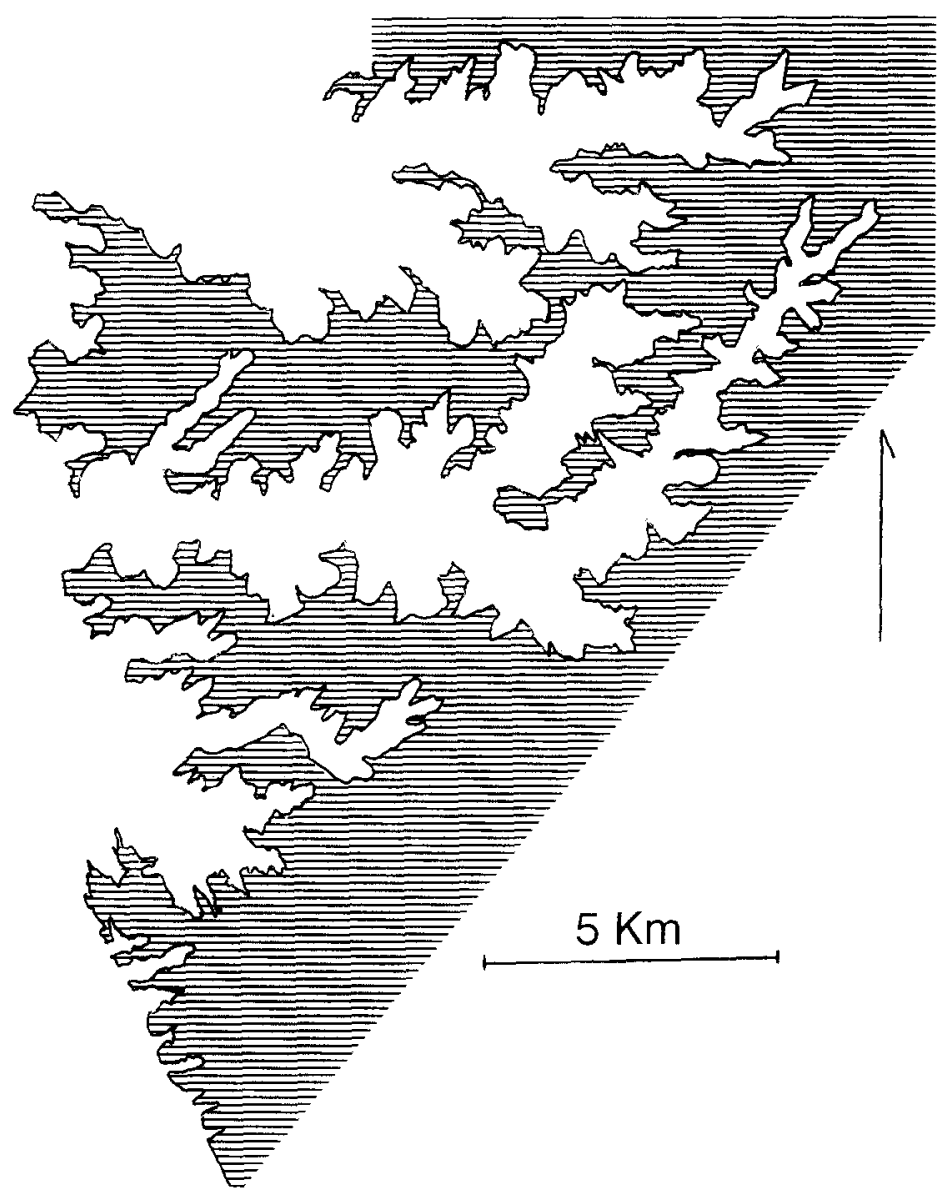

Fig. 10. Natural scarp in Navajo sandstone eroded by groundwater sapping. The interior, uneroded upland is patterned (Kayenta, AZ 1:100,000 quadrangle).

tend to be linear or crudely dendritic, with nearly constant width, and rounded rather than sharp terminations. in accord with the predictions of Ahnert (1960) and Laity and Malin (1985). Inclusion of a finite critical discharge $q_{\mathrm{c}}$ results in valley retreat diminishing and eventually ceasing as available uplands contributing discharge become smaller. The last stages of dissection occur along a narrow zone, producing sharply pointed valley heads. Groundwater flow is strongly influenced by fracture systems. This can be modeled by introducing linear zones of enhanced permeability, representing fracture zones, and results in a highly reticulate sapping valley system. Superimposition of backwasting (Fig. 11) produces a scarp in which early stages of dissection are dominated by headward retreat of sapping valleys. As the contribution of water from uplands diminishes during later stages of scarp retreat, backwasting becomes the dominant process and broadly curved reentrants and sharply pointed headlands are created.

The two parameters governing areal variability of permeability also affect scarp form. High variability of permeability creates a more irregular scarp form, whereas low variability produces a regular, symmetrical scarp form. If most of the variability is at high frequencies (large fractal dimension), or is spatially uncorrelated, the scarp form is irregular in detail but the overall pattern of valley development is regular. By contrast, for variance primarily at low frequencies (large wavelength), valley planforms are smooth at small scales, but the overall pattern of dissection becomes irregular, with a few large valley systems penetrating along zones of higher permeability. 


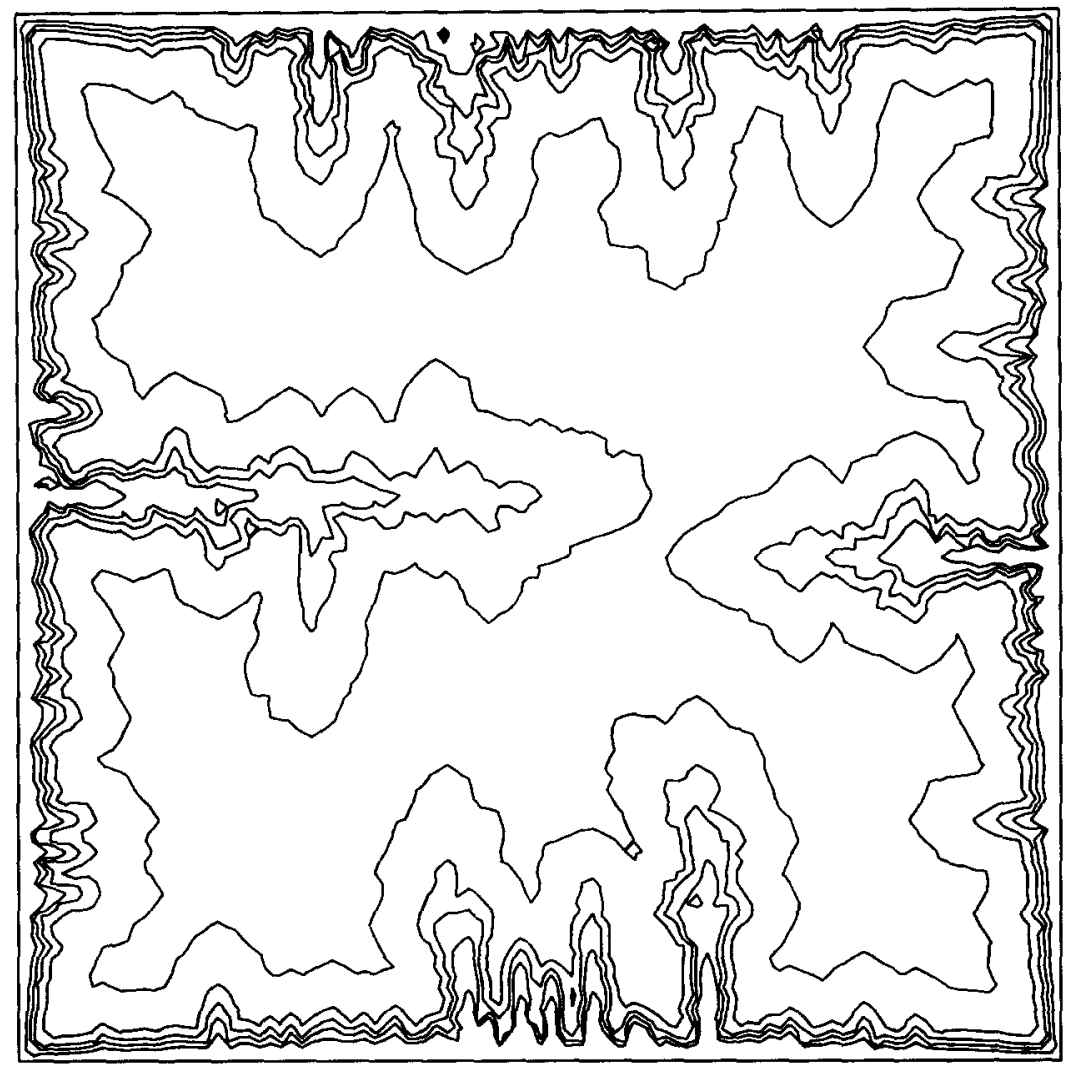

Fig. 11. Groundwater sapping simulation with superimposed scarp backwasting.

Stark (1994) shows that scarp retreat by groundwater sapping governed by Eq. (5) can be considered to be a type of diffusion-limited aggregation (Witten and Sander, 1981; Peitgen et al., 1992, pp. 475-480).

\subsection{Summary of scarp modeling}

These simulations illustrate a common evolutionary sequence. For natural scarps, early stages are characterized by a planform determined largely by the agency first exposing the scarp, generally fluvial downcutting along a master stream. Thus, scarp walls parallel the stream course with small reentrants along tributaries draining over the scarp. In the simulations the initial conditions are the imposed initial shape, either square or round. Continuing tributary erosion by fluvial or sapping processes with modest rates of superimposed uniform backwasting eventually creates a maximally crenulate scarp planform. As backwasting continues and upland areas diminish, rates of erosion by streams or sapping diminish relative to uniform backwasting (which may accelerate as relief increases). The scarp planform becomes characterized by broad reentrants, sharp cusps, and often isolated small buttes during the last stages before complete caprock removal (Figs. 7b, 8 and 11 ). Fig. 12 shows the temporal variation in the rate of overall erosion, the fraction of erosion occurring via backwasting, and the fractional uneroded upland for a sapping simulation similar to that in Fig. 11; a similar pattern occurs for mixed fluvial-backwasting scarp erosion. This sequence can occur on a single large mesa, as takes place in the simulations, but it is also illustrated by spatial sequences during long-continued erosion of a given caprock from newly exposed caprock in structurally low areas to the last caprock remnants in structurally high areas (e.g., the sequence from deep, narrow reentrants in the northern portions of Fig. 6 to broad, rounded reentrants in the southern portions).

Even slight structural dips create a strong asymmetry of rates of fluvial and sapping headcutting on downand up-dip facing portions of the scarp, because surface and subsurface drainage divides tend to be located close 


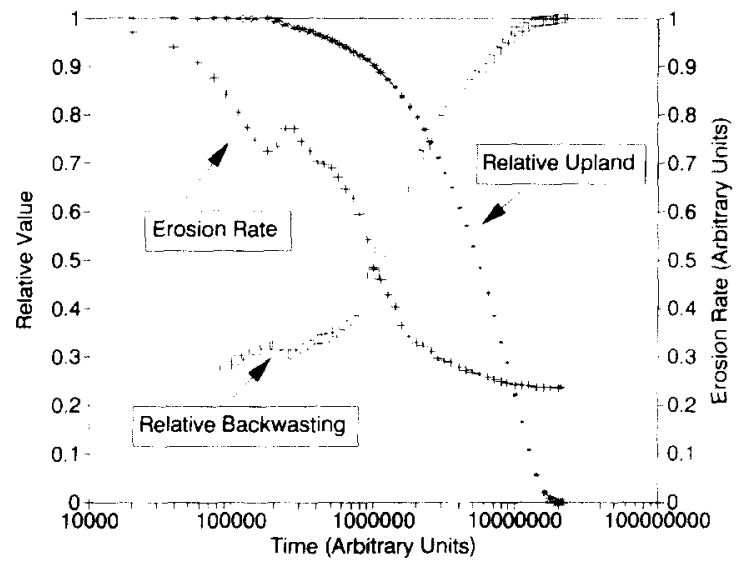

Fig. 12. Temporal characteristics of a sapping simulation similar to that shown in Fig. 11 governed by Eq. (5). "Erosion Rate" is the combined erosion rate from sapping and backwasting processes; " "Relative Backwasting'" is the fraction of the total erosion rate from backwasting; and "Relative Upland" is the remaining fraction of the original scarp area.

to the up-dip crest. General scarp backwasting is less affected by dip, so that up-dip scarp segments are nearly linear whereas down-dip sections are highly crenulate (Fig. 5; see also Howard and Selby, 1994, their fig. 7.47).

Deep reentrants that are essentially constant in width with rounded ends imply either that almost all valley enlargement occurs at the headward end of the valley ( see, for example, the sapping simulations in Fig. 9c) or that a period of rapid headward canyon growth (either by sapping or fluvial incision) is succeeded by a period of uniform scarp backwasting in later stages of erosion as upland areas contributing to surface or groundwater sapping diminish in size (e.g., Fig. 7).

\section{Morphometric characterization of scarp planform}

The simulation models produce scarp planforms that visually resemble natural scarps thought to originate by processes similar to those being modeled. More definitive validation of the model, however, requires quantitative comparison of natural and simulated scarps. Conversely, the morphology of natural scarps may allow inference of the erosional processes responsible for formation.

A suite of statistical measures of planform geometry are introduced below for landforms that exhibit system- atic features with superimposed irregularities. These techniques are applicable to closed forms (e.g. islands or buttes) and open forms (many escarpments, valley systems, local shorelines, etc.), and they can be objectively applied to any wiggly line.

The input data are a set of $x, y$ coordinates describing the edge of the landform, either from simulation runs or from digitized values of natural features. The step length should be short enough to accurately portray the smallest features of the planform that are of interest (or are resolvable). The coordinates, or " nodes", need not be equally spaced, because they are resampled in the analysis to a "nominal spacing" at equal distance increments; for simulated scarps the nominal spacing is one-half the grid spacing, and for natural planforms it is the average spacing between digitized nodes. All dimensional variables are initially expressed in units of the nominal spacing. Several types of variables are measured on the planforms; these are discussed briefly below and defined in Appendix 1.

\subsection{Transition analysis}

The transition analysis characterizes successive values of planform curvature. The analysis proceeds along the planform, noting the values of the angular curvatures at each node (local curvatures, or $l c$ ) and the curvature value at the node immediately before the local one (preceding curvatures, or $p c$ ). In general, $l c$ and $p c$ curvatures are directly correlated, so that a plot of average of $p c$ curvatures as a function of $l c$ curvature bins shows a positive slope through the origin (Fig. 13a). At high values of $l c$ curvature, however, the trend reverses, indicating that sharp bends tend to be succeeded by straighter segments (Fig: 13a). Planforms such as meandering streams tend to have long, uniformly curved loops with high positive correlation between successive segments (a slope approaching unity in Fig. 13a), but exhibit very few large curvatures and few very straight segments (Fig. 13b). By contrast, fluvial or sapping scarps have greater irregularity (lower slope in Fig. 13a), a greater spread of curvature values (Fig. 13b) and, in many cases, an asymmetry between positive and negative curvatures (Fig. 13a).

\subsection{Curvature statistics}

The moments of the curvature series are calculated (average, variance skewness, and kurtosis) as are its 

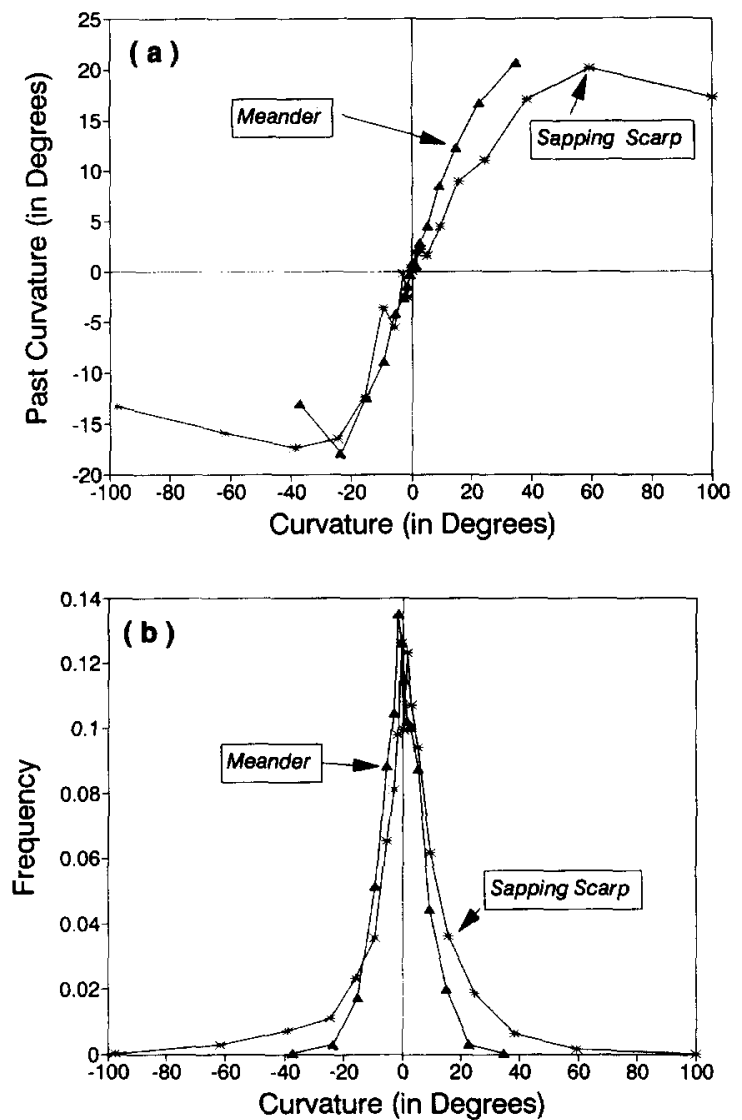

Fig. 13. Relationship between local planform curvature and lag-one values of curvature (transition analysis). (a) Lag-one curvatures for a meandering stream and natural scarp eroded by groundwater sapping; (b) frequency of local curvatures as a function of local curvature.

spectral characteristics (the spectral peak, the average spectral wavelength, and the coefficient of variation of the frequency).

\subsection{Planform generalization}

A number of statistics are related to successive generalization of the original planform using a sequence of "calipers" of increasing length. A caliper starts at the nominal spacing and is successively doubled in length six times. Two methods of generalization are used. The first, "path-cutting" method uses the caliper to walk along the curve, creating a new series of nodes (Fig. 14a) defined by the successive closest intersections of the original trace (including the straight lines between the digitized points) with the caliper. The rate of change of the total scarp length as the caliper length is increased is measured; this is equivalent to the divider method of fractal dimension measurement (e.g. Lam and De Cola, 1993b).

The other, "tangential" curve generalization technique involves finding a generalized planform that, using the caliper, totally encloses the original planform. The caliper is centered on a node and rotated counterclockwise (assuming the inside of the landform lies to the left side when moving from the beginning to the end of the trace), starting from the direction pointing toward the node preceding the present node. When the rotating line defined by the caliper points first intersects a node or line segment on the original curve, that intersected node or point along the segment becomes the
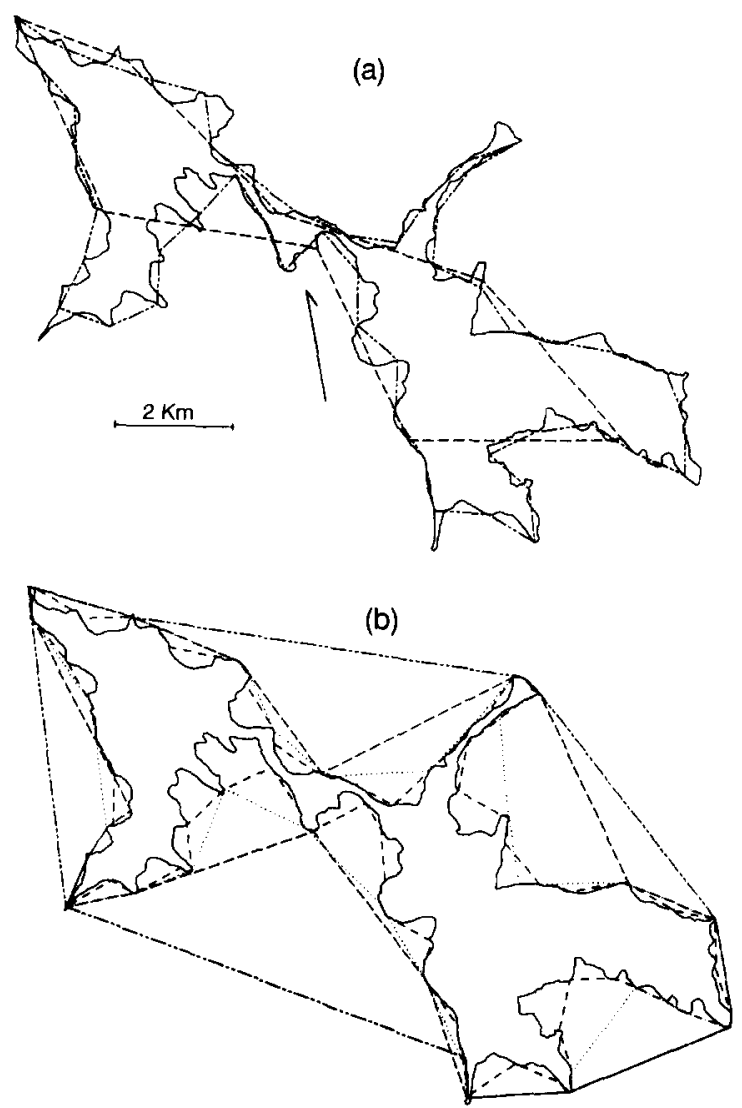

Fig. 14. Scarp generalization methods. (a) Path-cutting generalization of a natural scarp ( solid line) using the walking divider method. For clarity only the final two stages of generalization are shown. (b) Exterior tangential generalization of a natural scarp. Note that the generalized curve is always exterior to the original curve. For clarity only the final four stages of generalization are shown (Hite Crossing and Hanksville 1:100,000 quadrangles). 
next node on the generalized curve, and the process is repeated from the new node. Using this technique, the distance between successive points on the generalized curve are not equal. Eventually, for a long-enough caliper, the generalized curve becomes completely convex relative to the landform inside (Fig. 14b). The tangential generalization can either proceed along the exterior (as in Fig. 14b) or the interior of the scarp.

The convex stepping approach has similarities to fractal modeling of form outlines such as the Koch or Hilbert curves (Mandelbrot, 1983; Peitgen and Saupe. 1988; Peitgen et al., 1992), which assume that a path develops by successive generations of elaboration of an original curve, either regularly or stochastically. The valleys or headlands defined by a tangential caliper can be considered to be a kind of elaboration of the generalized curve. A variety of variables are defined which characterize (1) the rate of change of scarp length with caliper length, (2) the fraction of original points included in the generalized curve (i.e., the proportion of the original curve that is tangent to the generalized curve), and (3) the size distribution and shape of the valleys (Fig. 14b) or headlands that are defined by the area included between the original and generalized planforms (Appendix 1).

\subsection{Summary variables and self-scaling}

These statistics form a large database for each planform. Two additional steps must be taken to produce a multivariate set of variables for input into the discriminant analysis; these are: (1) selecting and summarizing the large number of measured variables into a smaller set for analysis; and (2) defining new variables which are functions of the original ones.

A number of the measured variables have dimensions of length and area and must be standardized for use in discriminant analysis. The approach is to define a nominal scale length. The scale length also has the purpose of specifying which of the various caliper lengths is selected for characterizing the included valley and headland geometry. The larger features of natural scarps (e.g. reentrants and headlands) are most diagnostic of the formative processes. Accordingly, the fifth stage of scarp generalization, at a scale 16 times the initial scale, was utilized to select the nominal values of many of the curve generalization statistics. This length is used to normalize variables with dimensions of length or area.

An important issue is whether there is in addition a characteristic "metric" for natural or simulated scarp forms at some level of generalization at which the scale dependency shows characteristic changes in response. If scarps were entirely self-similar at different scales or resolutions, thus defining a fractal, then no intrinsic scale length exists. In the simulations, the development of self-similarity is limited at smaller scales by the grid spacing and at the largest scale by the grid dimensions. The lower limit is a particularly important issue because, for simple versions of the backwasting, sapping, and fluvial models, no intrinsic lower limit exists. For example, discharge of DuPuit groundwater flow to scarp edges is directly proportional to contributing area per unit scarp length, and is, thus, self-similar for geometrically similar scarps of different absolute size. If scarp retreat by sapping were a power function of discharge, scarp faces would become infinitely elaborated into a curve with fractal dimension greater than unity (Stark. 1994). Similarly, fluvial networks are well approximated as fractals, at least until the scale of individual hillslopes is approached ( Tarboton et al., 1988). When examining natural scarps, however, a lower limit exists to self-similarity. For example, the headwalls of scarps eroded by groundwater sapping have extraordinarily smooth, uniform curvature over the width of the headwall, which may be several hundred meters across (Laity and Malin, 1985; Howard and Kochel, 1988: Howard and Selby, 1994). Similarly, fluvially incised scarps generally have a finite number of channels debauching over the scarp face, and smaller streams may have negligible impact upon scarp planform. A variety of limiting factors might determine the lower limit of self-similarity for natural processes. For example, loss of water by evaporation or percolation may restrict active seepage faces and attendant sapping to scarp front locations having collection areas on the top of the scarp above some critical threshold. This is included in the present model in the parameter $q_{\mathrm{c}}$. Similarly, for fluvial erosion, a critical threshold of source area $\left(A_{c}\right)$ or shear stress may exist. The most important lower limit may be, however, the caprock thickness. Failure of scarp caprocks because of undermining generally occurs as thin sheets extending from the top to the base of the caprock and as wide or wider than the cliff height. In the simulation models it is assumed that 
the grid scale corresponds to this intrinsic limiting scale. For natural scarps the digitizing interval should be selected so as to be equal to or smaller than the intrinsic scale. For the simulated scarps the matrix dimensions determines the upper scale, whereas for natural scarps the geologic and physiographic situation limits the size of scarps.

An important issue: does an intrinsic scale exist between the lower limiting scale and the upper limit of scarp size? This has been addressed empirically by examining the response of the variables defined in Appendix 1 as a function of the caliper length. Several variables exhibit a "critical" caliper length at which they have a maximum or minimum, or at which they exhibit a maximum rate of change. Variables measuring the shape of the included headlands or valleys typically show such extrema. Several variables express the caliper length at the maxima, minima, or maximal rate of change (Appendix 1). As will be seen, these scaledetermining variables are useful in distinguishing between different types of scarps.

The final step in reduction of variables was to summarize scale-dependency. The values of many variables were analyzed by regression to determine dependency upon caliper length; the slope from this regression for each variable was utilized.

Using these techniques of summarization, the very large number of original measurements was reduced to 122 summary variables. The correlations between these variables were examined for all measurements on digitized natural and simulated planforms. For sets of variables whose correlation ( pairwise or in multiple linear dependency) was greater than \pm 0.9 , all but one of the variables was deleted from the set. This reduced the number of variables to 71 used in the discriminant analysis (this reduction was done primarily to simplify interpretation and exposition; the stepwise discriminant analysis that is used would automatically limit inclusion of more than one of a set of highly correlated variables).

\subsection{Application to natural and simulated planforms}

The ability of these variables to distinguish between scarps formed by different processes was tested using a discriminant analysis. Discriminant analysis is a statistical technique by which $K-1$ (or fewer) optimal linear functions of the input variables are derived which best separate, or discriminate, between samples from $K$ known (a priori) populations with the assumption that each population is multivariate normal (Kleinbaum and Kupper, 1978; Davis, 1986). Nine classes of planforms have been defined a priori. Five of these correspond to the types of simulation models discussed above, namely backwasting, rounded backwasting, groundwater sapping, fluvial, and rounded fluvial. In addition to the simulated scarp planforms, natural scarps inferred to originate via these processes were also included. Four other types of natural planforms were included to test the discriminating power of the variables; these are Hopi buttes, stream meanders, lava flows, and mountain fronts sculpted by glacial erosion. Planforms for simulated and natural landforms are treated in three ways during the simulations. Some of the planforms are classified a priori as being strongly representative of one of the defined classes (the primary cases). Some planforms are classified a priori but either involve a small component of other processes, or are somewhat influenced by initial boundary conditions (the secondary cases). Finally, a number of simulated planforms are transitional between the defined classes (e.g., cases about equally influenced by backwasting and fluvial processes) or are strongly influenced by the initial scarp planform because they occur early in simulations. In addition some natural scarps have uncertain balances of fluvial, sapping and backwasting processes. These are the ungrouped cases. Definition and selection criteria for these planform classes are discussed below.

Backwasting: Eight simulations were conducted with the sole erosional process being backwasting governed by Eq. (1). The simulations differed in values of the three parameters governing the average, variance, and scale dependency of the spatially fractal random variation of erodibility. These simulations resulted in 38 scarp planforms, 38 used as primary cases. Three natural scarps characterized by broad, shallow reentrants and pointed headlands (e.g., Figs. 1 and 14) were used as primary cases, and three simulated scarps with mixed sapping and backwasting processes were used as primary cases.

Rounded backwasting: Thirteen simulated scarp planforms from two simulations were assigned as primary cases, with no secondary cases. No natural scarps were identified in this class. 


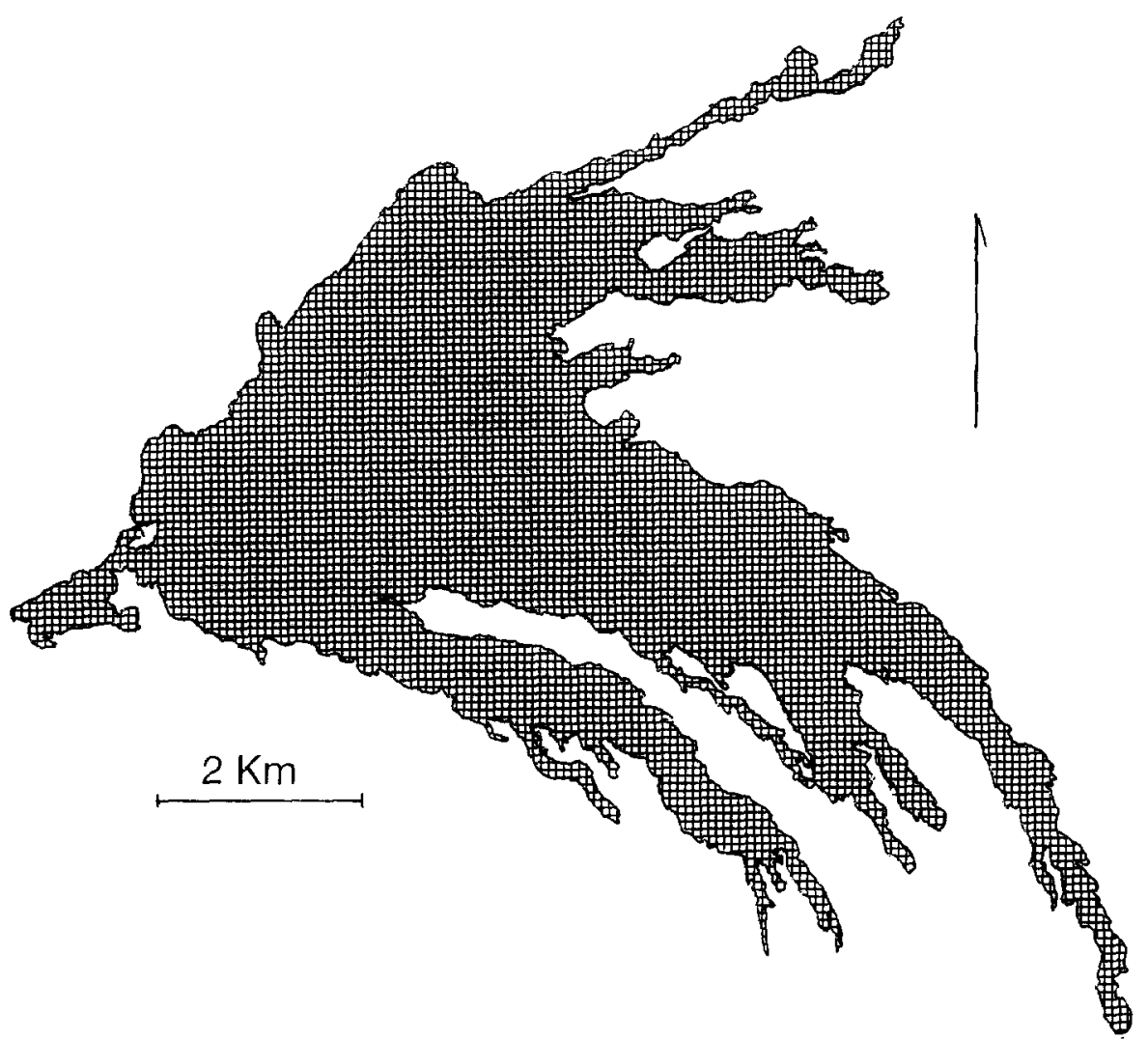

Fig. 15. A fresh lava flow (patterned) from the island of Hawaii (from Wolfe, 1988).

Sapping: Seventy-six simulations were conducted using Eq. (5) as the controlling rate law with various values of $C_{\mathrm{s}}, a, q_{\mathrm{c}}, C_{\mathrm{e}}$, and $K$. These simulations also include runs with varying average, variance and scale dependency of the fractal variation in $K$, as well as some simulations with an inclined caprock or with linear zones of enhanced permeability. Six natural scarps and 113 simulated scarps are primary cases, and two natural scarps and 151 simulated scarps served as secondary cases. The natural scarps are all developed in Navajo Sandstone (e.g., Fig. 10), where a dominance of sapping processes in valley extension was established by field studies of Laity and Malin (1985) and Howard and Kochel (1988).

Fluvial: Seventeen simulations were conducted using Eq. (3) as the rate law with various combinations of the controlling parameters $K_{\mathrm{f}}, K_{\mathrm{e}}, A_{\mathrm{c}}, K_{\mathrm{fc}} / K_{\mathrm{fn}}, T$, and $K_{e}: \partial z /\left.\partial t\right|_{\mathrm{e}}$. Of the 85 resulting planforms, 63 were primary cases and 6 were secondary cases. Five natural scarps were used as primary cases and 3 as secondary cases. Natural scarps were identified as being domi- nated by fluvial erosion of reentrant valleys if welldefined upland streams debauched over the scarp from the scarp top- or back-slopes and if the reentrant canyons terminated in sharp notches not much wider than the stream (e.g., Fig. 6). Unlike the sapping scarps, a dominance of fluvial over sapping erosion was not validated in the field.

Rounded fluvial: Four simulations with 17 planforms were conducted with convexity-enhanced backwasting. Seven of these are primary cases and 1 is a secondary case. In addition, 2 natural scarps are primary cases and 1 is a secondary case. The natural scarps were selected based upon a predominance of rounded headlands and sharply terminated reentrant valleys (e.g. Fig. 4).

Meander: Seven natural meandering planforms are primary cases and 17 are secondary cases. These streams were selected from those studied by Howard and Hemberger ( 1991 ).

Lava: Six geologically recent and uneroded lava flows, digitized from geologic maps containing lava 


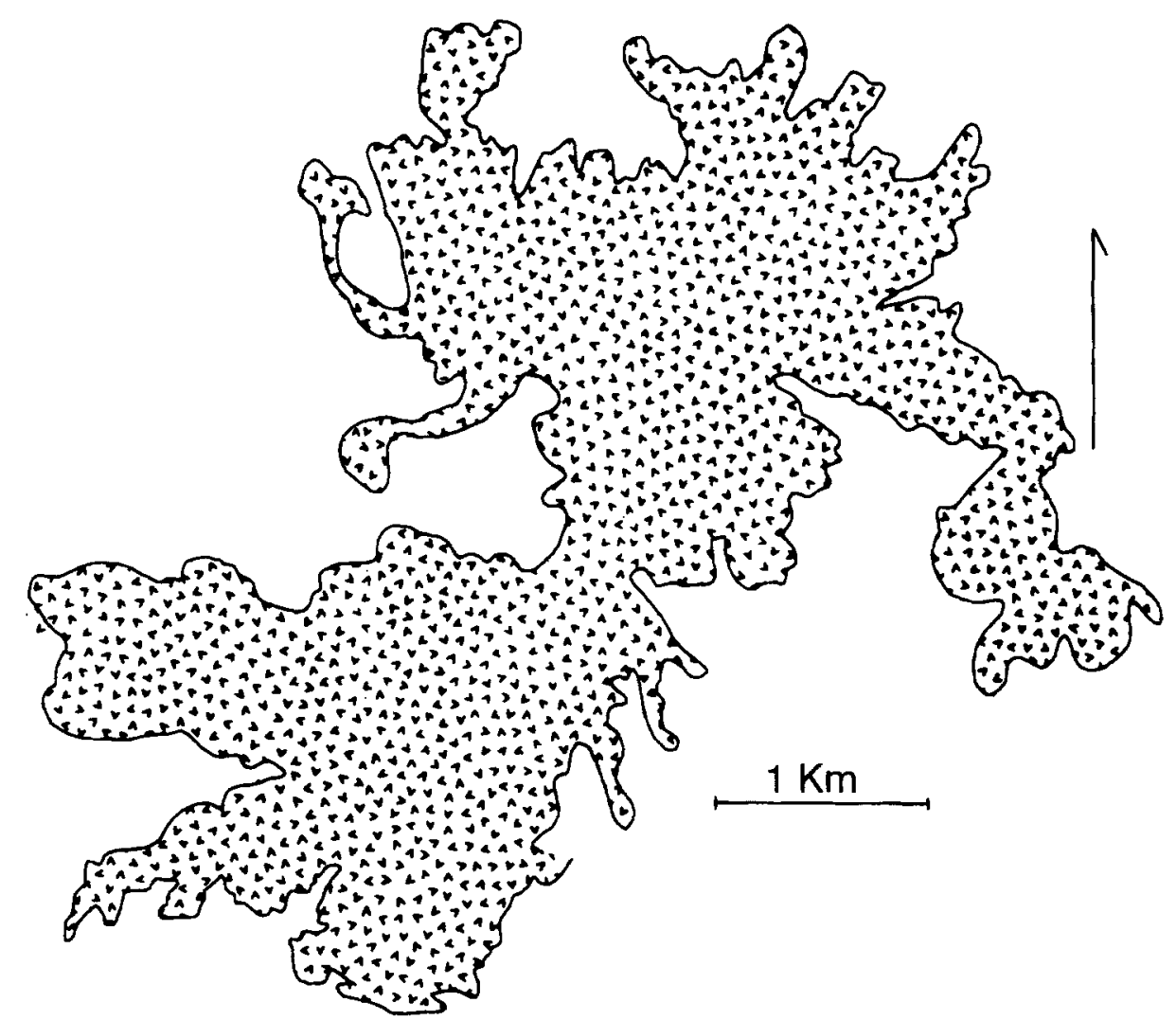

Fig. 16. A Hopi Butte. The interior, uneroded upland is patterned (Hauke Mesa and Dilkon 1:24,000 quadrangles).

flows in the northwest continental United States and Hawaii, were used as primary cases, and an additional 6 were secondary cases (Fig. 15).

Hopi: The Hopi Buttes of Arizona are tabular igneous intrusives into sedimentary rocks. The sedimentary rocks have been eroded from around the intrusives, leaving buttes with rounded planforms (Fig. 16). In some cases slight fluvial incision has occurred on the edges. In addition to the Hopi buttes, this category also includes 4 lava-capped buttes in northeastern New Mexico and southeastern Colorado. Thirteen of the planforms were primary cases, and 6 are secondary cases.

Glacial: Glaciation of previously fluvially eroded mountains creates a distinctive landscape of U-shaped valleys, rounded cirques, residual aretes, and skeletonized divides. Eight skeletonized divides from Montana, Utah, and Alaska were digitized by tracing along the mountain front at an altitude just above the cirque floors (e.g., Fig. 17). Four of these served as primary cases, and 4 as secondary cases.
Ungrouped cases included 2 natural scarps, 11 digitized contours from topographic maps in uniform, hilly terrain, and 164 simulated planforms.

The discriminant analysis, thus, involves 9 classes of scarps with a total of 279 primary and 199 secondary cases. The discriminant analysis was conducted using SPSS (Norusis, 1992). Because of large differences between the total length of the planform, the cases were weighted (the simulated planforms average 630 nodes in length, whereas the natural planforms average 3700 nodes, with several exceeding 10,000 nodes). The confidence interval for a population statistic estimated by a sample from a normal population varies inversely with the square root of the sample size. Correspondingly, each case was weighted by the square root of the number of digitized points involved. An important issue in discriminant analysis is the total number of classification functions to be used. Up to seven discriminant functions would be statistically significant for this data set, but the last few functions offer little additional discriminating power. Use of two functions, 


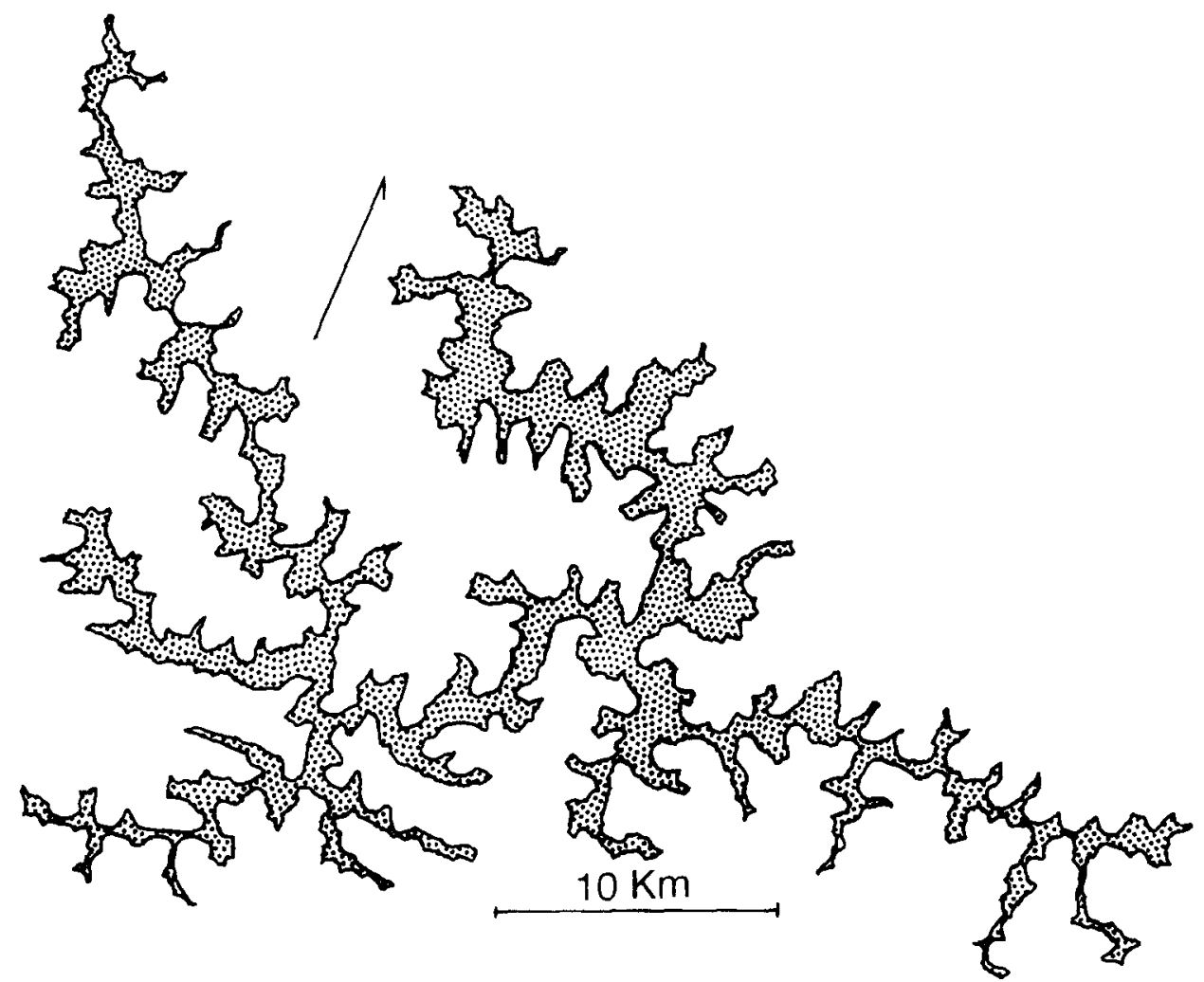

Fig. 17. A skeletalized, glacially modified mountain range in Alaska. The range is patterned (Philip Smith Mountains, $1: 250,000$ quadrangle).

including both primary and secondary cases for defining the classification function, results in correct classification of $77 \%$ of the defining cases. When the number of functions is increased to four, however, the percentage of correctly classified cases increases to $87 \%$. Adding two more functions only increases the percentage to $90 \%$ correct. Four functions were utilized in the results discussed below.

Discriminant analyses were conducted with three sets of defining cases, that is, cases used to calculate the classification functions. One analysis utilized only the primary cases, resulting in correct classification of $91 \%$ of the primary cases, but only $62 \%$ of the secondary cases were classified correctly. A lesser success in classifying the secondary cases would be expected both because they were not used to define the discriminating functions and because they are less certain in their a priori classification. A second analysis grouped all the primary and secondary cases, and one-half of these were randomly selected to define the classification functions. Ninety-one percent of the defining cases were correctly classified, but only $78 \%$ of the reserved. or validation cases were correctly classified. The final analysis, reported here, utilized both the primary and secondary cases to define the classification functions, with $87 \%$ of the cases being correctly classified.

The results of the classification, Fig. 18, shows all of the cases (defining, secondary, and unclassified) plotted according to scores on the first two discriminating functions. The fences separating the classification regions for the 9 planform classes are also shown. In plotting the cases, the symbols for correct and incorrect classification are defined with regard to the use of all four discriminant functions. Table 1 summarizes the classification of the defining and ungrouped cases.

Table 2 shows the normalized weightings of the morphometric variables on the four discriminant functions. These weightings indicate the relative contribution of the variables to the discriminant function. The discriminant functions are related to different aspects of scarp morphology:

Function 1: This function is strongly positively weighted for meanders and, to a lesser extent, lava flows and the Hopi buttes. Glacial and sapping scarps 

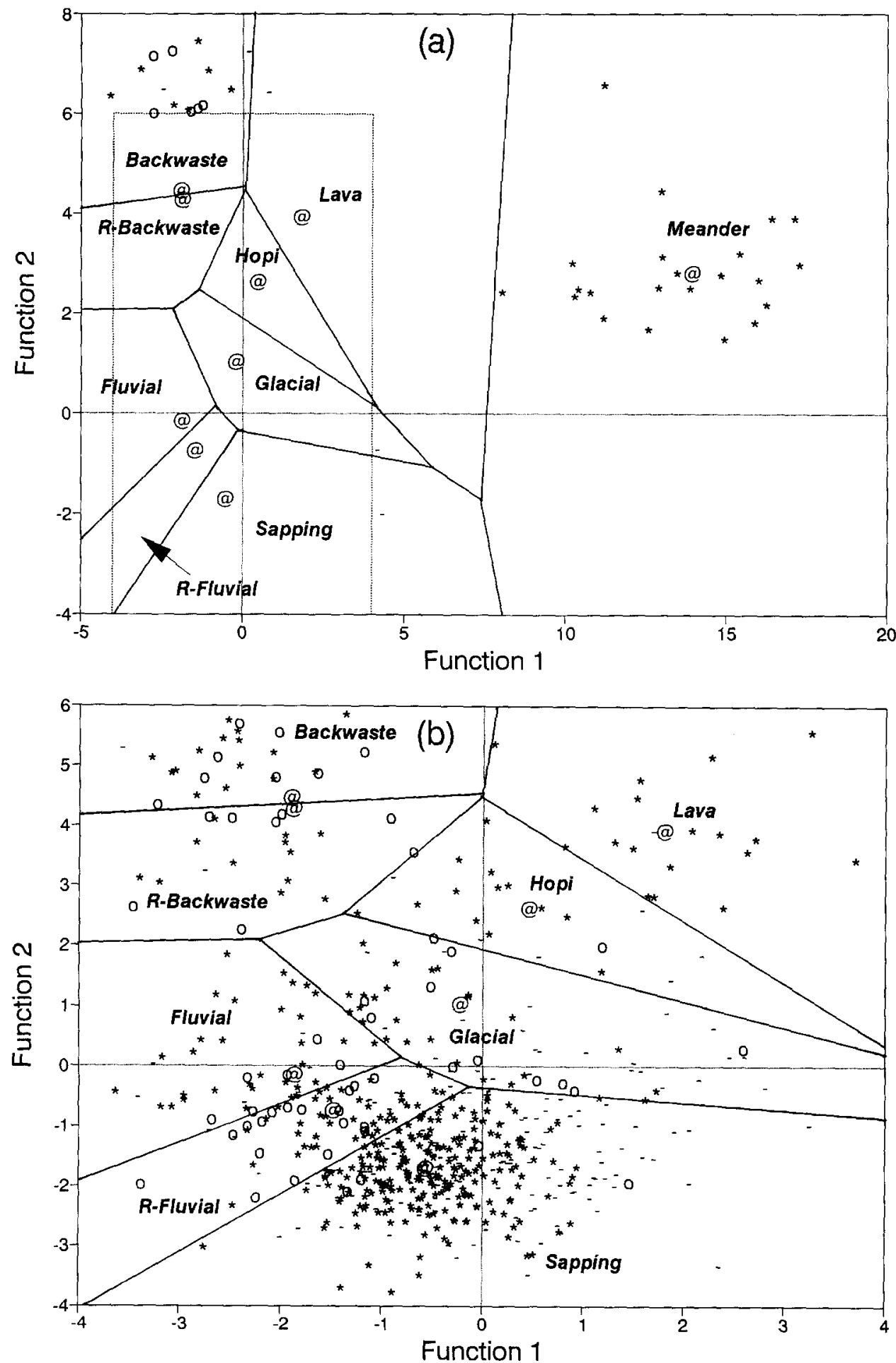

Fig. 18. Discriminant classification of 9 classes of natural planforms. Only the first two discriminating functions are shown. Lines show the classification boundaries. Sample means for the 9 classes are shown by "@". Cases classified a priori and correctly grouped by the four discriminant functions are shown by "*", whereas misclassified cases are shown by " 0 ". Cases that were given no a priori classification are shown by "_.". (a) Overall view of the classification. The dashed box is shown in greater detail in (b), and cases falling within the box are not plotted. (b) Detail of (a) showing individual cases. 
Table 1

Discriminant classification results. Ungrouped cases were not assigned a priori membership. The a priori group is the pre-assigned classification and the predicted group is the classification from the discriminant analysis. A 'successful' classification occurs if the a priori and predicted groups are equal.

\begin{tabular}{|c|c|c|c|c|c|c|c|c|c|c|}
\hline \multirow{2}{*}{$\begin{array}{l}\text { A priori } \\
\text { group }^{a}\end{array}$} & \multirow{2}{*}{$\begin{array}{l}\text { Total } \\
\text { cases }\end{array}$} & \multicolumn{9}{|c|}{ Predicted group } \\
\hline & & 1 & 2 & 3 & 4 & 5 & 6 & 7 & 8 & 9 \\
\hline 1 & 270 & 258 & 8 & 0 & 0 & 4 & 0 & 0 & 0 & 0 \\
\hline 2 & 77 & 4 & 50 & 4 & 0 & 17 & 0 & 0 & 0 & 2 \\
\hline 3 & 44 & 1 & 0 & 30 & 0 & 0 & 0 & 0 & 0 & 3 \\
\hline 4 & 19 & 0 & 0 & 0 & 17 & 1 & 0 & 0 & 1 & 12 \\
\hline 5 & 11 & 0 & 0 & 0 & 0 & 11 & 0 & 0 & 0 & 0 \\
\hline 6 & 24 & 0 & 0 & 0 & 0 & 0 & 24 & 0 & 0 & 0 \\
\hline 7 & 8 & 0 & 0 & 0 & 0 & 0 & 0 & 7 & 1 & 0 \\
\hline 8 & 12 & 0 & 0 & 0 & 0 & 0 & 0 & 0 & 12 & 0 \\
\hline 9 & 13 & 0 & 2 & 4 & 0 & 0 & 0 & 0 & 0 & 7 \\
\hline Ungrouped & 177 & 124 & 18 & 1 & 6 & 17 & 0 & 0 & 3 & 8 \\
\hline
\end{tabular}

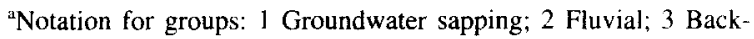
wasting; 4 Hopi Buttes; 5 Rounded fluvial; 6 Meander; 7 Glacial; 8 Lava flows; 9 Rounded backwasting.

tend to be neutrally weighted, and fluvial and backwasting scarps are negatively weighted. The positively weighted classes tend to have smoothly varying planforms with few abrupt changes of curvature and a frequency spectrum dominated by long wavelengths, whereas the negatively weighted scarps have a more irregular planform with abrupt changes of planform direction and a wide range of size of features.

Function 2: This function primarily distinguishes between negative values for sapping and fluvial scarps with deep reentrant valleys versus positive values for planforms with planforms that are generally not strongly indented, such as backwasting scarps, lava flows, and Hopi buttes. Variables that are positively weighted on this function describe scarp features characterized by broad, shallow reentrants and projections. In addition, for negatively weighted planforms the planform is overall more varied (higher standard deviation of curvature). Furthermore, because of the deep, narrow reentrants and projections in sapping and fluvial scarps, the tangential generalization shortens the pathlength rapidly at small caliper lengths, with less change for large caliper lengths than in the case of the positively weighted planforms.

Function 3: Hopi Buttes, meanders, lava flows and rounded fluvial scarps are positively weighted on this function, whereas backwasting, rounded backwasting, and sapping scarps are negatively weighted. Negative

Table 2

Structure matrix: Pooled within-groups correlation between variables and discriminant function scores. Only variables with correlations greater than \pm 0.15 are shown

\begin{tabular}{|c|c|c|c|c|}
\hline \multirow[t]{2}{*}{ Variable } & \multicolumn{4}{|c|}{ Function } \\
\hline & 1 & 2 & 3 & 4 \\
\hline$T-C V S L P$ & - & -0.20 & - & - \\
\hline$T-S D R A T$ & - & - & -0.41 & - \\
\hline$T-C A T D I F F$ & - & -0.15 & -0.27 & -0.16 \\
\hline T-POSRAT & - & 0.16 & -0.18 & - \\
\hline T-NEGRAT & - & - & 0.22 & -0.15 \\
\hline T-RANGE & - & -0.15 & - & - \\
\hline$C \cdot C V-S D$ & & -0.35 & 0.15 & 0.18 \\
\hline$C \cdot C V-S K$ & - & - & 0.27 & 0.16 \\
\hline$C-S P-M X$ & - & - & - & -0.15 \\
\hline$C-S P-A V$ & 0.64 & - & - & - \\
\hline$C-S P-S E$ & 0.36 & -0.16 & - & - \\
\hline$E C \cdot L N-D X-L$ & - & 0.26 & - & -0.16 \\
\hline$I C-L N-D X-L$ & - & 0.17 & - & - \\
\hline$E I C-L N-S$ & - & 0.25 & -0.18 & - \\
\hline$E I C L-L N-S$ & - & -0.15 & - & -- \\
\hline$E / C-W I D-S$ & - & - & 0.15 & - \\
\hline$E / C-W I D-D 2$ & - & 0.17 & - & -0.16 \\
\hline$I C L-L N-D X-L$ & - & - & - & 0.18 \\
\hline$E C l-L N-D X-L$ & - & 0.18 & - & - \\
\hline$I C-F R$ & 0.15 & - & - & -0.19 \\
\hline$E C-A R-9-S$ & - & - & 0.16 & -0.18 \\
\hline$E C-L P-9-S$ & - & - & - & -0.21 \\
\hline$I C-L P-9-S$ & - & 0.17 & - & - \\
\hline$E C-L P-9-D 2$ & - & 0.16 & - & -0.15 \\
\hline$I C \cdot L P-9-D 2$ & - & 0.24 & - & - \\
\hline$E C-W I D-9-S$ & - & 0.22 & - & -0.16 \\
\hline EC-PRAT-9 & - & -0.39 & - & $\ldots$ \\
\hline IC-PRAT-9 & - & -0.31 & - & - \\
\hline$E C-D I S-S E-9$ & - & - & -0.19 & - \\
\hline$E C-D I S-S K-9$ & - & 0.16 & - & -0.15 \\
\hline$I C-D I S-S K-9$ & - & 0.23 & - & - \\
\hline$E C \cdot D I S-K R-9$ & - & - & 0.17 & -0.17 \\
\hline$I C-D I S-K R+9$ & - & - & 0.20 & - \\
\hline EC-SHAPE1-7-MX & - & -0.22 & - & - \\
\hline IC-SHAPE1-7-MX & - & -0.28 & 0.28 & 0.26 \\
\hline EC-SHAPE 1-7-MX-L & - & 0.17 & 0.22 & - \\
\hline IC-SHAPE1-7-MX-L & - & 0.21 & - & - \\
\hline IC-SHAPE1-7-DX & - & -0.22 & 0.26 & 0.19 \\
\hline EC-SHAPE1-7-DX-L & - & - & 0.15 & -0.17 \\
\hline EC-SHAPE1-9-MX & - & -0.27 & -0.16 & \\
\hline IC-SHAPE1-9-MX & - & -0.25 & - & 0.29 \\
\hline$I C-S H A P E 1-9-M X-L$ & - & 0.27 & - & - \\
\hline EC-SHAPE $-9-M X-L$ & - & 0.20 & - & -0.22 \\
\hline EC-SHAPE2-9-MN & - & 0.18 & $\ldots$ & - \\
\hline IC-SHAPE2-9-MN & - & 0.33 & -0.16 & - \\
\hline EC-SHAPE2-7-MN-L & - & - & 0.22 & - \\
\hline$I C-S H A P E 2-9-M N-L$ & - & 0.17 & - & -- \\
\hline$E C \cdot N U M B-9-S$ & - & - & -0.19 & 0.15 \\
\hline EC-NUMB-9-D2 & - & $\ldots$ & - & 0.23 \\
\hline$I C \cdot N U M B-9-D 2$ & - & -0.20 & - & - \\
\hline
\end{tabular}


weightings on this function are associated with variables characterizing ( 1 ) broadly rounded reentrants and a tendency for pointed projections (asymmetrical planforms); (2) a strong irregularity of planform at small spatial scales (curvature values of adjacent points are not strongly correlated); (3) valleys that are either very shallow or very narrow and deep.

Function 4: Glacial scarps are strongly negatively weighted on this function, with lava flows and meanders slightly negatively weighted. All other planforms are slightly positively weighted. The variables that provide the negative weightings for glacial scarps describe the large spatial scale of the major features, the tendency for headlands to be long and sharply pointed, the low overall variability of curvature, and the broadly curved reentrants.

The discriminant functions are reasonably successful in classification accuracy. They are most successful with the sapping, glacial, Hopi Butte, rounded fluvial, lava flow, and meander planforms (Table 1). Misclassifications are usually to closely related landforms, such as backwasting and rounded backwasting, fluvial and rounded fluvial, lava flows and Hopi Buttes. Fluvial, sapping and backwasting scarps are intergradational in nature, and this is reflected in some cross-classifications ( Table 1).

Because of the large number of measured variables and the small sample sizes for each scarp class, some success in classification would be expected even if the cases were randomly selected. A purely random a priori assignment of cases among the 9 classes would result in $11 \%$ being correctly classified on the average. Ten discriminant analyses were conducted with 478 cases being randomly selected (without replacement) and randomly pre-classified with the same total numbers per class as in the classification shown in Fig. 18 and Table 1. The percentage "correctly" classified by the discriminant analysis using the same 71 variables varied from $16 \%$ to $37 \%$, averaging $25 \%$. Thus, the $87 \%$ correct classification in the present analysis is a very large improvement over a random classification, indicating (1) that the a priori assignment of cases to the different classes of scarps has a strong basis, (2) that the collection of variables performs well in distinguishing between different types of scarp morphology, and (3) the classification has reasonably strong power against false classification (Type II errors).

\section{Discussion}

The simulation models of the development of scarp planform in layered rocks via backwasting, groundwater sapping, and fluvial erosion seem to produce reasonable approximations of natural patterns of scarp retreat. One respect in which the models fail to represent natural scarps is that spatial variations in scarp relief are not accounted for; rates of retreat on scarps presumably increases with relief, and relief is greatest on portions of the scarp that have been exposed longest or have the highest structural elevation. In addition, the scarp models do not account for process variations in front of the scarp because of, for example, spatially variable rates of fluvial erosion of the scarp rampart. More explicit modeling of scarp profile and relief would be needed to address these issues.

A number of variables for characterizing morphology of scarp planform have been introduced in this paper. Some types of these variables are more useful than others in distinguishing between scarps formed by different processes (Table 2 ). The statistical moments of the spatial series of planform curvature are useful, as are variables summarizing the spectrum of the curvature series. The statistics summarizing lag-one curvature relationships (transition analysis) have high discriminating power, as do a number of variables summarizing the geometry of reentrants and headlands defined by the tangential curve generalization. On the other hand, the most common measure of the fractal dimension of lines on a plane, the slope of the line relating the logarithm of curve length to measuring caliper length in path-cutting generalization ( $P-L N-S$ in Appendix 1), is ineffective in discriminating between classes of scarps.

For planar curves the use of tangential generalization is strongly related to fractals, because it involves successive generalization of the original curve and it is conceptually inverse to the successive elaboration methods of generating fractal curves (e.g., Koch and Hilbert curves).

Ideally, a few (5-10) easily measured, intuitively appealing variables would suffice to classify planforms into genetic classes. Unfortunately, such "killer" variables have not been identified by this study. The variables utilized in this paper certainly do not capture all aspects of planform geometry, nor are they necessarily the most efficient for differentiating between classes of 
scarps. Further analysis of the curvature time series. such as fitting autoregressive and moving average models (Box and Jenkins, 1976) might yield additional discriminating power. Additionally, some types of planforms have frequent outliers, particularly backwasting scarps breaking up into buttes; the linear density of outliers could be measured. Finally, if attention is limited to closed planforms, additional measures are possible, such as ratios of perimeter to area and the distribution of distances of points from the center of gravity of the planform.

The pragmatic approach of defining, and empirically evaluating the utility of, a suite of variables to characterize scarp morphology contrasts with widespread efforts to define a few "universal" statistics, often driven by theoretical models. An instructive example is the use of stream order to measure branching statistics, such as bifurcation ratios, and ratios of stream length and drainage area. These were initially proposed as utilitarian measures by Horton (1945), who hoped to characterize regional variations in hydrologic response using them. These ratios, however, are remarkably invariant with respect to geology, relief, structure, and climate, and they are ineffective in characterizing flood response ( Howard, 1990b). These and similar measures of branching characteristics were saved from well-deserved obscurity by the development of theoretical models of stream networks, first the random model of Shreve $(1966,1967,1969)$ and more recently the fractal paradigm (Tarboton et al., 1988; La Barbera and Rosso, 1989; Robert and Roy, 1990: Stark, 1991; Rinaldo et al., 1992; Phillips. 1993). As a result, the geomorphological and hydrological literature is replete with analyses of branching statistics. whereas attention has been diverted from the definition and use of parameters which summarize differences between stream networks (e.g., measures of basin shape, hypsometry, straightness of flowpaths, etc.). and which are useful in characterizing flood response (Howard, 1990b) and differences in formative processes. Any model of branching that allows for a range of topological structures, whether it embodies a random or a systematic selection criterion, is likely to produce an ensemble of networks that statistically obeys Horton's "laws" (Kirchner, 1993).

A similar situation has emerged with respect to measurement of surfaces and lines. The emergence of fractal models in geology and geophysics (Turcotte, 1992;
Korvin, 1992; Lam and De Cola, 1993a) has focused attention on one measure - the fractal dimension. Fractal surfaces and lines can be generated by a variety of processes, and fractal lines with visually quite distinct patterns (and different formative processes) can have equal fractal dimensions. As noted above, the fractal dimension serves poorly in distinguishing between scarps formed by different processes. The recognition of scale limitations of self-similar formative processes has led to the recognition of multi-fractals and techniques for identifying the multiple fractal dimensions and the scales of transition (e.g., Evertsz and Mandelbrot, 1992; De Cola, 1993; Lavalee et al., 1993 ). Nonetheless, if geomorphologists wish to contrast landscapes or compare models with reality, the restriction of comparative statistics to estimates of fractal dimension(s) will afford limited discriminatory power and poor confirmation.

\section{Acknowledgements}

This research was supported by a NASA Planetary Geology and Geophysics grant NAGW-1926. The manuscript was substantially improved as a result of suggestions by J.W. Kirchner and David Furbish.

\section{Appendix 1. Definition of variables}

Conventions for naming variables are summarized in Appendix 2. Each variable name is a hyphenated combination of type of analysis, property measured, and summary statistic. For many properties the summary statistical moments (average $A V$, standard deviation $S D$, skewness $S K$, and kurtosis $K R$ ) are measured. Details of the properties measured for each type of analysis are presented below.

\section{Transition analysis}

The local curvatures $l c$ at each node are assigned to one of 20 bins with boundaries of $0, \pm 1, \pm 2, \pm 4$, $\pm 7, \pm 12, \pm 20, \pm 30, \pm 50$ and \pm 80 degrees and the statistical moments of the preceding curvatures $p c$ are summarized within each bin. These lag-one curvature transitions are summarized in a number of parameters, each prefixed with " $T-$ ": (1) the frequency and 
moments of $p c$ curvatures within the central two bins (between \pm 1 degrees) ( $T$-CENT-FR, $T$-CENT-SD, $T$ CENT-SK, T-CENT-KR); (2) the moments for all $p c$ curvatures ( $T$-ALL-SD, T-ALL-SK, T-ALL-KR); (3) the difference between the average $p c$ in the $2^{\circ}$ to $4^{\circ}$ bin and that in the $-2^{\circ}$ to $-4^{\circ}$, divided by the range ( 6 degrees) (T-CVSLP); (4) for the $l c$ curvature bins that have the greatest and smallest $p c$ curvature averages the $l c$ bin averages ( $T$-POSCAT and T-NEGCAT) are recorded as well as the maximum and minimum $p c$ curvature averages ( $T$-POS-MX,T-NEG-MN) in these bins; and (5) the average $p c$ curvatures in the \pm 50 90 degree $l c$ curvature ranges ( $T$-POS-AV, T-NEG$A V)$. The discriminant analysis uses combinations of these variables that are defined as follows: (1) $T-D I F F$, the difference between T-POS-MX and T-NEG-MN divided by $T-A L L-S D$; (2) T-POSNEG, the sum of $T$ $P O S-M X$ and $T-N E G-M N$ divided by $T-A L L-S D ;(3)$ $T$-SK-DIFF, the difference between $T-C E N T-S K$ and $T-A L L-S K$; (4) $T-K R-D I F F$, the difference between $T$ $C E N T-K R$ and $T-A L L-K R$; (5) T-SDRAT, the ratio of $T$-CENT-SD to T-ALL-SD; (6) T-POSRAT, the difference between T-POS-MX and T-POSCAT divided by $T-A L L-S D$; (7) $T$-NEGRAT, the difference between $T-N E G-M N$ and T-NEGCAT divided by T-ALL-SD; (8) T-RANGE, the sum of T-POSAVG and T-NEGAVG divided by $T-A L L-S D$; and (9) T-CATDIFF, the difference between T-POSCAT and T-NEGCAT divided by $T-A L L-S D$.

\section{Curvature statistics}

The summary statistical moments of the curvature series $C V$ are prefixed by $C$ - (i.e., $C-C V-A V, C-C V-S D$, $C-C V-S K$, and $C-C V-K R$ ). Also measured are the spectral peak $C-S P-M X$, the average spectral wavelength, $C-S P-A V$, and the coefficient of variation of the frequency $C-S P-C V$ (see Howard and Hemberger, 1991, for formal definitions).

\section{Planform generalization}

For the path-cutting curve generalization the total scarp length $P-L N$ is measured for each of the 7 caliper lengths $L C A L I P E R$. Thus $P-L N$ and other variables from curve generalization are a vector of values, one for each LCALIPER.
The tangential curve generalization can proceed along the exterior $(E)$ (Fig. 14b) or interior $(I)$ of the scarp. Two techniques are used for searching beyond the present location for the intersection of the rotating caliper with the original planform. In the first, "complete" $(C)$ search all points further along the scarp are examined (up to $25 \%$ of the total length of the scarp), whereas the second, "limited" $(L)$ search includes only points lying within a distance (following the planform) of twice the caliper length. The two search techniques differ in the case of deep reentrant valleys or long headlands, in that the complete search will close off a large valley in one step when the caliper length equals the width of the mouth of the valley or base of the headland, whereas the limited search more gradually generalizes the planform. Thus there are four classes of tangential generalization variables depending upon interior or exterior stepping and complete or limited look-ahead; variables are designated according to method as $I C-, I L-, E C$-, and $E L$-.

As with the path-cutting method, the total scarp length (e.g., IC- $L N$ ) is calculated. In addition, because the generalized planform encloses the original planform, the area included between the two planforms is measured (e.g., EL-AR). The fraction of the original points included in the generalized curve is also measured, that is, proportion of the original curve that is tangent to the generalized curve (e.g., $I L-F R$ ).

A number of derivative variables related to the curve generalization are defined. These are:

$E I C-L N$ : The average of $E C-L N$ and $I C-L N$.

$E I L-L N: \quad$ The average of $E L-L N$ and $I L-L N$.

EIC-WID: EC-AR plus IC-AR divided by EIC-LN.

This is a measure of the average separation between the interior and exterior generalized curves.

EIL-WID: $E L-A R$ plus $I L-A R$ divided by $E I L-L N$.

Most of the statistics related to the exterior or interior tangential curve generalization concern the geometry of the areas included between the original curve and the generalized curve. These are reentrant "valleys" in the case of exterior generalization and "headlands" for interior generalization. Each valley is defined by the nodes at the beginning and end of the valley, the set of original nodes describing the perimeter of the valley, and the "enclosing" line along the generalized curve joining the beginning and end points and enclosing the valley. Two additional locations are defined, 
the coordinates $x_{\mathrm{c}}, y_{\mathrm{c}}$ at the center of the line joining the endpoints, and the center of gravity of the valley, $x_{\mathrm{g}}, y_{\mathrm{g}}$. For each valley or headland a number of variables are measured:

$A R$ :

The area of the enclosed valley.

PER: The perimeter of the valley (including the enclosing line).

$L P$ :

The largest perpendicular distance between the original nodes and the enclosing line.

$L C$ :

The largest distance between the original nodes and $x_{c}, y_{\cdots}$

WID: The ratio of $A R$ to $L P$. an average valley "width".

PRAT: The ratio of the length of the original curve to PER.

$D I S-A V, D I S-S D, D I S-\quad$ The moments of the $S K, D I S-K R$ : distribution of distances between nodes on the original curve and $x_{\mathrm{g}}, y_{\mathrm{g}}$.

LRAT: The ratio of $L C$ to $L P$.

SHAPE1: $A R$ times four pi divided by the square of $P E R$.

SHAPE2: $A R$ times four pi divided by the square of $L P$.

These statistics are generated for each enclosed valley or headland, and then the arrays holding these statistics are ordered by increasing magnitude of $L P$. The average value of these statistics for the 70-80th percentile and for the largest 10 percent are saved as $A R$ 7. $A R-9$, etc. In addition, the number of valleys or headlands in these percentile classes (NUMB) is also recorded. Because a different set of headlands or valleys are defined for each of the four methods of tangential curve generalization, each of the above variables is also qualified by the generalization method (e.g., IL-AR-7, EC-SHAPE2-9, EL-NUMB-9, etc.). These statistics are calculated and stored for each value of the defining caliper length.

The shape variable $S H A P E 1$ generally exhibits a maximum at a particular value of $L C A L I P E R$. The maximum value $(M X)$ and the caliper length $(L)$ are recorded (e.g. IC-SHAPE1-7-MX and EC-SHAPE 1-9$M X-L)$. Similarly SHAPE 2 is examined for its mini- mum value and associated $L C A L I P E R$. The generalized curve length $L N$ also is examined for the $L C A L I P E R$ value at which the greatest decrease in length $(D X)$ occurs (e.g. IC-LN-DX-L).

Most of the variables related to tangential curve generalization exhibit a regular variation with $L C A L I P E R$. These scale-dependent variations are analyzed by regression using the range of caliper lengths from $0.25 x$ to $4.0 x$ the nominal caliper length ( 16 times the digitizing scale). A log-linear relationship was assumed:

$\ln (Y)=I+S \ln ($ LCALIPER $)$

where $Y$ is the variable and $I$ and $S$ are the estimated slope and intercept, respectively. In addition, for many variables the rate of change of the slope with respect to caliper length, $D 2$, was also calculated. Again, $-S$, and $-D 2$ are suffixed to variable names to indicate use of these summary values.

\section{Appendix 2. Notation}

Notation for morphometric variables. See text for additional description.

Notation Explanation

A. Prefixes for type of analysis

$T$ - $\quad$ Curvature transitions

C- $\quad$ Curvature time series

P- $\quad$ Planform generalization using path cutting

IL- Interior tangential planform generalization using limited look-ahead

IC- Interior tangential planform generalization using complete look-ahead

EL- Exterior tangential planform generalization using limited look-ahead

$E C$ - Exterior tangential planform generalization using complete look-ahead

B. Type of property measured

$L N \quad$ Length, measured in units of step length

$A R \quad$ Included area, measured in units of step length squared

$C V \quad$ Planform planimetric curvature

$S P \quad$ Planform curvature spectrum

C. Percentile range for headland and valley analysis

-7- $\quad$ Average value in 70 th to 80 th percentile range 
-9. Average value in largest 10 percentile range (90th to 100 th)

D. Suffix for type of statistic

$-A V \quad$ Average

$-S D \quad$ Standard deviation

-SK Skewness

$-K R \quad$ Kurtosis

$-F R \quad$ Relative frequency

$-M X \quad$ Maximum value

$-M N \quad$ Minimum value

$-S \quad$ Rate of change as a function of caliper length

$-D X \quad$ Maximum rate of change as a function of caliper length

$-D 2 \quad$ Curvature of rate of change ( $2 \mathrm{nd}$ derivative)

$-L \quad$ Caliper length associated with $-M X,-M N$, or $-D 2$

\section{References}

Ahnert, F., 1960. The influence of Pleistocene climates upon the morphology of cuesta scarps on the Colorado Plateau. Ann. Am. Assoc. Geogr., 50: 139-156.

Baker, V.R., Kochel, R.C., Laity, J.E. and Howard, A.D., 1990. Spring sapping and valley network development. In: C.G. Higgins and D.R. Coates (Editors), Groundwater Geomorphology. Geol. Soc. Am. Spec. Pap., 252: 235-265.

Box, G.P. and Jenkins, G.M., 1976. Time Series Analysis: Forecasting and Control. Holden-Day, Oakland, California, 575 pp.

Davis, J.C., 1986. Statistics and Data Analysis in Geology. 2nd. ed. Wiley, New York, $646 \mathrm{pp}$.

Davis, W.M., 1901. An excursion into the Grand Canyon of the Colorado. Harv. Mus. Comp. Zool. Geol., 5: 105-201.

De Cola, L., 1993. Multifractals in image processing and process imaging. In: N.S.-N. Lam and L. De Cola (Editors), Fractals in Geography. Prentice-Hall, Englewood Cliffs, pp. 282-304.

Dutton, C.E., 1882. Tertiary history of the Grand Canyon district. U.S. Geol. Surv. Monogr. 2.

Evertsz, C.J.G. and Mandelbrot, B.B., 1992. Multifractal measures. In: H.-O. Peitgen, H. Jurgens, and D. Saupe, Chaos and Fractals: New Frontiers of Science. Springer, New York, pp. 921-953.

Fournier, A., Fussell, D. and Carpenter, L., 1982. Computer rendering of stochastic models. Commun. Assoc. Comp. Mach., 25: 371-384.

Goodchild, M.F., 1980. Fractals and the accuracy of geographical measures. Math. Geol., 12: 85-98.

Horton, R.E., 1945. Erosional development of streams and their drainage basins: Hydrophysical approach to quantitative morphology, Geol. Soc. Am. Bull., 56: 275-370.

Howard, A.D., 1970. A study of process and history in desert landforms near the Henry Mountains, Utah. PhD Dissertation, Johns Hopkins University, Baltimore, unpubl.

Howard, A.D., 1971a. Simulation of stream networks by headward growth and branching. Geogr. Anal., 3: 29-50.

Howard, A.D., 1971b. Simulation model of stream capture. Geol. Soc. Am. Bull., 82: 1355-1376.

Howard, A.D., 1972. Problems in interpretation of simulation models of geologic processes. In: M.M. Morisawa (Editor), Quantitative Geomorphology: Some Aspects and Applications. Publications in Geomorphology, Binghamton, NY, pp. 61-82.

Howard, A.D., 1988a. Equilibrium models in geomorphology. In: M.G. Anderson (Editor), Modelling Geomorphological Systems. Wiley, Chichester, pp. 49-72.

Howard, A.D., 1988b. Groundwater sapping experiments and modeling. In: A.D. Howard, R.C. Kochel and H.E. Holt (Editors), Sapping Features of the Colorado Plateau. Natl. Aeronaut. Space Adm. Spec. Pap., SP-491: 71-83.

Howard, A.D., 1990a. Theoretical model of optimal drainage networks. Water Resour. Res., 26: 2107-2117.

Howard, A.D., 1990b. Role of hypsometry and planform in basin hydrologic response. Hydrol. Proc., 4: 373-385.

Howard, A.D. and Hemberger, A.T., 1991. Multivariate characterization of meandering. Geomorphology, 4: 16l-186.

Howard, A.D. and Kerby, G., 1983. Channel changes in badlands. Geol. Soc. Am. Bull., 94: 739-752.

Howard, A.D. and Kochel, R.C., 1988. Introduction to cuesta landforms and sapping processes on the Colorado Plateau. In: A.D. Howard, R.C. Kochel and H.E. Holt (Editors), Sapping Features of the Colorado Plateau. Natl. Aeronaut. Space Adm. Spec. Pap., SP-491: 6-56.

Howard, A.D. and Selby, M.J., 1994. Rock Slopes. In: A.D. Abrahams and A.J. Parsons (Editors), Geomorphology of Desert Environments. Chapman and Hall, London, pp. 123-172.

Kirchner, J.W., 1993. Statistical inevitability of Horton's laws and the apparent randomness of stream channel networks. Geology, 21: 591-594.

Kirkby, M.J., 1986. A two-dimensional simulation model for slope and stream evolution. In: A.D. Abrahams (Editor), Hillslope Processes. Allen and Unwin, Winchester, pp. 203-222.

Kleinbaum, D.G. and Kupper, L.L., 1978. Applied Regression Analysis and Other Multivariable Methods. Duxbury Press, North Scituate, Mass., 566 pp.

Korvin, G., 1992. Fractal Models in the Earth Sciences. Elsevier, Amsterdam, $396 \mathrm{pp}$.

La Barbera, P. and Rosso, P., 1989. On the fractal dimension of river networks. Water Resour. Res., 25: 735-741.

Laity, J.E. and Malin, M.C., 1985. Sapping processes and the development of theater-headed valley networks in the Colorado Plateau. Geol. Soc. Am. Bull., 96: 203-217.

Lange, A.L., 1959. Introductory notes on the changing geometry of cave structures. Cave Studies 11.

Lam, N.S.-N. and De Cola, L. (Editors), 1993a. Fractals in Geography. Prentice-Hall, Englewood Cliffs, 308 pp.

Lam, N.S.-N. and De Cola, L., 1993b. Fractal measurement. In: N.S.N. Lam and L. De Cola (Editors), Fractals in Geography. Prentice-Hall, Englewood Cliffs, pp. 23-55. 
Lavalee, D., Lovejoy, S., Schertzer, D. and Ladoy, P., 1993. Nonlinear variability of landscape topography: Multifractal analysis and simulation. In: Lam, N.S.-N., and L. De Cola (Editors), Fractals in Geography. Prentice-Hall, Englewood Cliffs, pp. 158-192.

Mandelbrot, B.B., 1983. The Fractal Geometry of Nature. Freeman. New York, $468 \mathrm{pp}$.

Nicholas, R.M. and Dixon, J.C., 1986. Sandstone scarp form and retreat in the Land of Standing Rocks, Canyonlands National Park, Utah. Z. Geomorphol., 30: 167-187.

Norusis, M.J., 1992. SPSS for Windows: Professional Statistic: Release 5. SPSS Inc., Chicago.

Phillips, J.D., 1993. Interpreting the fractal dimension of river net works. In: N.S.-N. Lam and L. De Cola (Editors), Fractals in Geography. Prentice-Hall, Englewood Cliffs, pp. 142-157.

Peitgen, H.-O. and Saupe, D. (Editors), 1988. The Science of Fractal Images. Springer, New York, 312 pp.

Peitgen, H.-O.. Jurgens, H. and Saupe, S., 1992. Chaos and Fractals: New Frontiers of Science. Springer, New York, 984 pp.

Rinaldo. A., Rodriguez-Iturbe, I., Rigon, R.. Bras, R.L.. ljjasz-Vasquez, E. and Marani, A., 1992. Minimum energy fractal structures of drainage networks. Water Resour. Res., 28: 2183-2195.

Robert, A. and Roy, A., 1990. On the fractal interpretation of the mainstream length drainage area relationship. Water Resour. Res., 26: 839-842.

Schipull, K. 1980. Die Cedar Mesa - Schichtstufe auf dem Colorado Plateau - Ein Beispiel fur die Morphodynamik arider Schichtstufen. Colorado Plateau. USA. Z. Geomorphol. 24: 180-191.
Schmidt, K.-H., 1980. Eine neue Methode zur Ermittlung von Stufenruck wanderungsraten, dargestellt am Beispiel der Black Mesa Schictstufe, Colorado Plateau, USA. Z. Geomorphol., 24: 180191.

Schmidt, K.-H.. 1988. Rates of scarp retreat: a means of dating neotectonic activity. In: V.H. Jacobshagen (Editor), The Atlas System of Morocco - Studies on its Geodynamic Evolution. Lect. Notes Earth Sci., 15: 445-462.

Schumm, S.A. and Chorley, R.J., 1966. Talus weathering and scarp recession in the Colorado Plateau. Z. Geomorphol., 10: 11-36.

Shreve, R.L.. 1966. Statistical law of stream numbers. J. Geol., 74: $17-37$.

Shreve. R.L., 1967. Infinite topologically random channel networks. J. Geol., 75: 397-414.

Shreve, R.L.. 1969. Stream lengths and basin areas in topologically random channel netorks. J. Geol., 77: 397-414.

Stark, C.P.. 1991. An invasion percolation model of drainage network evolution. Nature, 352: 423-425.

Stark, C.P., 1994. Cluster growth modeling of plateau erosion. J. Geophys. Res., 99: 13957-13969.

Tarboton, D.G., Bras, R.L. and Rodriguez-Iturbe, I., 1988. The fractal nature of river networks. Water Resour. Res., 24: 1317-1322.

Turcotte, D.L., 1992. Fractals and Chaos in Geology and Geophysics. Cambridge Univ. Press, Cambridge, $221 \mathrm{pp}$.

Witten. T.A. and Sander, L.M., 1981. Diffusion-limited aggregation: A kinetic critical phenomenon. Phys. Rev. Letters, 47: 14001403

Wolfe, E.W. (Editor). 1988. The Puu Oo eruption of Kilauea Volcano, Hawaii: Episodes 1 through 20, January 3, 1983, through June 8. 1984. U.S. Geol. Surv. Prof. Pap., 1463. 